\title{
Wealth Concentration, Income Distribution and Alternatives for the USA
}

\section{Lance Taylor, Ozlem Omer and Armon Rezai}

\section{Schwartz Center for Economic Policy Analysis (SCEPA)}

Department of Economics

The New School for Social Research

6 East 16th Street, New York, NY 10003

economicpolicyresearch.org

Suggested Citation: Taylor, L., Ozlem, O., and Rezai, A. (2015) "Wealth Concentration, Income Distribution, and Alternative for the USA." Schwartz Center for Economic Policy Analysis and Department of Economics, The New School for Social Research, Working Paper Series 2015-6. 


\title{
Wealth Concentration, Income Distribution, and Alternatives for the USA
}

\author{
Lance Taylor, Özlem Ömer, and Armon Rezai*
}

September 2015

\begin{abstract}
US household wealth concentration is not likely to decline in response to fiscal interventions alone. Creation of an independent public wealth fund could lead to greater equality. Similarly, once-off tax/transfer packages or wage increases will not reduce income inequality significantly; ongoing wage increases in excess of productivity growth would be needed. These results come from the accounting in a simulation model based on national income and financial data. The theory behind the model borrows from ideas that originated in Cambridge UK (especially from Luigi Pasinetti and Richard Goodwin).
\end{abstract}

JEL codes: D31, D33, D58, B50

Keywords: Wealth distribution, income distribution, Cambridge theory

* New School for Social Research, supported by the Institute for New Economic Thinking. 


\section{Introduction}

In the "long run," or at least in two-century simulations of the demanddriven model of economic growth described herein, the share of the top one percent of US households in the distribution of wealth could rise from around $40 \%$ to $60 \%$. Ever-increasing concentration of wealth along the lines suggested by Thomas Piketty (2014) is not likely to occur.

On the other hand, it would be very difficult to reduce wealth inequality significantly just by using policy measures such as taxes on capital gains or net worth. Andrew Mellon, Secretary of the Treasury under the string of Republican presidents in the 1920s, said that "During a Depression, assets return to their rightful owners." In fact, he was wrong. Under almost all circumstances, assets move toward "rightful" households who already hold a preponderant share. To get that share back below $40 \%$ and keep it there, the market needs an actor with countervailing power against the accumulation of the very rich. Creation of an institution such as a public wealth fund to out-save the savers would be required to mitigate their control of national net worth.

Wealth of households comprises residential capital plus a stock of claims on business firms which own productive capital and on financial liabilities issued by government and the rest of the world. Income is a flow of payments per unit time - along with capital gains saving from payments flows cumulates into the stocks. In the short run income inequality can be reduced by one-shot measures such as boosting low wages or raising taxes at the top. But even if applied aggressively these moves will not erase income differentials between the rich and the poor or middle class unless new resources can be directed toward lower income households. Higher labor productivity (output per person-hour) can provide such a flow of resources. After 1980, however, US productivity gains favored the top one percent because wage growth did not keep up. Economic surplus moved from almost all other households toward the very rich.

Without the potential benefits of productivity growth, the economy resembles a zero-sum game in which the saving required to finance new assets created 
by investment or a fiscal deficit comes largely from households with high incomes. If output is fixed, then the lower their saving rate, the higher their income (mostly from profits) must be. John Maynard Keynes (1930) called this theorem of accounting a "widow's cruse." ${ }^{1}$ In fact, shifts in output do affect savings flows as emphasized a few years later by Keynes (1936), and go together with income redistribution to balance demand injections and saving leakages in the simulations reported below.

\section{Outline}

The road to these conclusions takes interesting turns. We proceed from the abstract to the concrete, beginning with a review of distribution and growth theories proposed by Cambridge University economists half a century ago. They concentrated on social relations and class conflict, with lessons soon forgotten by the mainstream but brought back into relevance by recent debate. Cambridge theory emphasizes how different income flows and wealth stocks affect the economic prospects of the social classes. The widow's cruse is one example. A more realistic narrative is that in a demand-driven growth model there can be a medium-term inverse relationship between the profit share and the level of economic activity, consistent with the data. Under standard assumptions, both mainstream growth theory and the widow's cruse impose the wrong sign on this linkage ${ }^{2}$.

Another complication that almost all growth theory lacks is an adequate description of how households get access to income from profits. Their capital gains on assets such as equity are an important vehicle. We take up their significance in the income and wealth distributions in the USA. A key empirical point for the

\footnotetext{
${ }^{1}$ In King James Bible used by Keynes, 1 Kings 17: 9-16 describes the prophet Elijah's flight from evil King Ahab. God provided Elijah and the widow with whom he was boarding oil in a cruse and flour. The more oil they consumed, the more they received.

${ }^{2}$ In mainstream models there can be a negative relationship if a parameter called the elasticity of substitution exceeds one - a value usually rejected by standard econometrics applied to the data.
} 
business sector is that financial transfers (dividends and interest) to households plus capital losses due to rising equity prices may outstrip net profits. Business

suffers paper losses which are transformed into apparent household increases in wealth. Capital gains at the top together with erosion of the labor share created a strong shift in the income distribution toward the richest one percent of US households. Their income share rose by ten percent after the mid-1980s - an enormous change by historical standards (Taylor et al., 2014). Our simulation model is constructed on the basis of the theory and data. We end the paper with its results and alternative scenarios of change. The model incorporates the usual convention of setting up a medium term macro equilibrium consistent with the national income and financial accounts, and then tracing its dynamics toward a "long run" steady state with all relevant variables growing at the same rate.

\section{Growth and the distribution of income and wealth}

Initial stylized analysis can be constructed around the functional (or profits vs. wages) income distribution, assuming that physical capital is the sole component of wealth. A mapping toward the size distribution is discussed below. For the moment, all profits are supposed to accrue directly to households, leaving out business saving, financial transfers, and capital gains. Households typically own only residential capital (subject to mortgage obligations) along with debt and equity claims on firms which hold productive plant and equipment. Financial linkages in the form of payments flows as well as claims on assets are all treated as veils covering but not affecting ultimate ownership of capital. A useful additional simplification is to follow Luigi Pasinetti $(1962,1974)$ in assuming that there are two classes of households - "capitalists" who receive profits on the capital they own, and "workers" who get the rest of income. 


\section{Demand and income distribution over the cy- cle}

We construct a medium run around the business cycle. Karl Marx observed a century and a half ago that an upswing in economic activity increases labor's bargaining power so that the share of profits in output (say $\pi$ ) tends to fall, i.e. there is a high employment "profit squeeze." ${ }^{3}$ In the same time frame, activity itself (conveniently measured by the output/capital ratio $u=X / K$ with $X$ as output and $K$ as the capital stock) is stimulated by increased investment due to a higher profit rate $r=\pi u$. Aggregate demand appears to be "profit-led."

There is controversy in the literature as to whether aggregate demand is profit- or wage-led. When one takes the size distribution of income into account, however, this distinction blurs. As emphasized by Piketty and illustrated below, wage dispersion has vastly increased over recent decades; moreover poor people have low positive or negative saving rates. Households near the bottom of the distribution receive a combination of wages and income transfers, and increasing their pay has a minimal impact on retained earnings. One can safely say that demand can be led by increases both in profits and low (partly wage) incomes.

The combination of a profit-squeeze distribution and profit-led output generates a predator-prey cycle along lines first formalized by Richard Goodwin (1967) Contemporary versions of Goodwin such as Barbosa-Filho and Taylor (2006) and Kiefer and Rada (2014) treat the wage share $\psi=1-\pi$ as predator and capacity utilization as prey. Both papers extend Goodwin in setting up dynamics of capacity utilization and the wage share. In continuous time (with $\dot{u}=d u / d t$ etc.) we have

$$
\dot{u}=h(u, \psi)
$$

as a representation of the Keynes (output adjustment) side of the model and

\footnotetext{
${ }^{3}$ As noted above, mainstream models postulate the opposite sign $-\pi$ rises when output swings up.
} 


$$
\dot{\psi}=j(u, \psi)
$$

describing Marx-Goodwin shifts in distribution.

These differential equations will be locally stable if $d h / d u<0$ and $d j / d \psi<0$. In the medium run, effective demand will be profit-led if $d h / d \psi<0$. There will be a profit squeeze if $d j / d u>0$. The opposite signs of the latter two "cross partial" derivatives suggest that a cycle is likely.

Figure 1 illustrates the dynamics. The $\dot{u}=0$ and $\dot{\psi}=0$ schedules are "nullclines" showing combinations of $u$ and $\psi$ that respectively hold the timederivatives $\dot{u}$ and $\dot{\psi}$ to zero. The small arrows show the directions in which $u$ and $\psi$ move when they are away from their nullclines. The negative slope of the $\dot{u}=0$ schedule can be interpreted to mean that aggregate demand is profit-led in the medium run; the positive slope of the $\dot{\psi}=0$ curve indicates that there is a profit squeeze à la Marx when output and employment go up.

[Figure 1 about here.]

Suppose that there is an initially low level of $u$ as at point A. Capital utilization will begin to rise toward its nullcline, and the wage share will fall. Later in the cycle $\psi$ will begin to increase. Eventually the rising labor share forces the trajectory to cross the $\dot{u}=0$ nullcline, and output declines from its cyclical peak. In a bit more detail, if $\omega$ is the real wage and $\xi$ is labor productivity then $\psi=\omega / \xi$. Productivity typically goes up as an economy emerges from a slump so $\psi$ falls. After a time a tighter labor market means that $\omega$ begins to rise, and $\psi$ increases after the trajectory crosses the $\dot{\psi}=0$ nullcline. Over recent decades in the USA, cyclicality has persisted but the whole relationship appears to have shifted downward (see below), increasing the profit share across cycles and contributing to growing income concentration at the top of the distribution.

Using long-term quarterly data for 13 wealthy OECD economies, Kiefer and Rada fit a discrete-time cross-country econometric model like the one illustrated in Figure 1, obtaining nullclines with relatively steep slopes in the $(u, \psi)$ plane, 
i.e. the economies are weakly profit-led but demonstrate a robust profit squeeze when economic activity rises. ${ }^{4}$ Typical fluctuations of the variables over the cycle are in the range of five to ten percentage points.

In the figure the intersection of the nullclines establishes a focal point $F$ around which the variables cycle. For our purposes, Kiefer and Rada's most significant result is that $F$ has moved southwest over time. Over four decades the wage share has dropped by around five percent and capacity utilization by two percent (before the Great Recession). Because the fall in $u$ is proportionately less than the decrease in $\psi$, the profit rate $r=(1-\psi) u$ has gone up.

\section{Growth with capitalists and workers}

Now we can take up the dynamics of wealth concentration. To keep the presentation as simple as possible, business cycle fluctuations are suppressed by replacing the Kiefer-Rada nullclines with "level" relationships.

As assumed above, capital $K$ is the sole component of wealth. It is not a "factor of production" subject to diminishing returns as in neoclassical models but rather serves to scale the system. Its associated profit flow $r K=\pi X$ is somehow made directly available to households, presumably via financial payments and capital gains. They do not engage in transactions involving debt.

The rich class of hereditary capitalists or rentiers hold capital $K_{c}$ to generate their income $r K_{c}$. Workers hold the rest of capital to get profits $r\left(K-K_{c}\right)$ and receive labor income as well. Shares of income saved by capitalists and workers are $s_{c}$ and $s_{w}$ respectively, with $s_{c}>s_{w}$. Their saving means that accumulation $\dot{K}^{S}$ can be expressed as

$$
\dot{K}^{S}=s_{c} r K_{c}+s_{w}\left[X-r K_{c}\right]-\delta K
$$

with $\delta$ as the rate of depreciation.

Dividing through by $K$, recalling that $r=\pi u$, and letting $Z=K_{c} / K$ gives

\footnotetext{
${ }^{4}$ Alternatively, the profit share rises sharply when capital utilization declines - a point of relevance below.
} 


$$
\hat{K}^{S}=\left[\left(s_{c}-s_{w}\right) \pi Z+s_{w}\right] u-\delta
$$

In this equation $\hat{K}^{S}$ is the capital stock growth rate $(\hat{K}=\dot{K} / K)$ permitted by available saving at economic activity level $u$ which depends on $\pi$ and the capital control ratio $Z$. A "profit effect" on saving and growth operates through changes in the income distribution $(\pi)$ and eventually wealth $(Z)$. Mainstream growth theory determines $\hat{K}^{S}$ in equation (4) from full employment, a neoclassical production function, etc., while fixing $u$ and $\pi$ at any time. With $Z$ set by "history" and pre-determined saving and depreciation rates the capital stock growth rate follows directly. ${ }^{5}$

To clarify assumptions built into equation (4), it helps to think in terms of a $19^{\text {th }}$ century distinction between not consuming a share of income (or "abstinence" on the right-hand side) and transforming the resulting saving into capital ("accumulation" on the left). Growth theory equates the two flows. Even assuming that in practice households can manage this transformation there is no reason to expect that higher fiscal or foreign "saving" (a government surplus or external deficit) will automatically feed into higher investment. See the simulations below.

Keynesian models bridge the abstinence/accumulation gap by bringing in an independent investment function and thereby effective demand. One way to do so is to follow Kalecki (1971) and introduce profit-driven investment,

$$
\dot{K}^{I}=g_{0} K+\alpha \pi X-\delta K
$$

or

$$
\hat{K}^{I}=g_{0}+\alpha r-\delta=g_{0}+\alpha \pi u-\delta .
$$

In these equations $g_{0}$ represents Keynesian animal spirits and capital stock

\footnotetext{
${ }^{5}$ The growth equations (3) or (4) and (8a) below will tend toward steady states on their own dynamics. Mainstream models always impose an additional restriction saying that steady state capital stock and population growth rates are equal, but in general there is no reason for this assumption to apply.
} 
growth responds to the profit rate (parameter $\alpha>0) .{ }^{6}$

By setting excess effective demand to zero, $\dot{K}^{I}-\dot{K}^{S}=0$, and solving we get an expression for $u$,

$$
\left[\left[\left(s_{c}-s_{w}\right) Z-\alpha\right] \pi+s_{w}\right] u=g_{0}
$$

A higher $Z$ raises saving and thereby reduces capital utilization in a demand driven model (the paradox of thrift applies). If aggregate demand is profit-led, i.e. $\left(s_{c}-s_{w}\right) Z-\alpha<0, u$ will respond positively to $\pi$.

In effect equation (6) replaces the $\dot{u}=0$ nullcline in Figure 1 for determination of $u$. Similarly, the relationship

$$
\pi=\theta(u)
$$

with $d \theta / d u<0$ replaces the $\dot{\psi}=0$ nullcline to set $\pi$ (and $\psi$ ) as a function of $u$.

See Figure 2. Following Kiefer and Rada the $\pi(u)$ schedule is steep, signaling a strong profit squeeze. A contractionary demand shock such as an increase in $Z$ or a reduction in government spending would shift the $\mathrm{u}(\pi, Z)$ schedule to the left. The result would be an increase in $\pi$ and a drop in $u .^{7}$ The implication is that $r=\pi u$ could move either way. In the simulations presented below a fall in capital utilization tends to be associated with a small increase in the profit rate and rate of growth. In other words, higher concentration of wealth can lead to low employment without a big growth pay-off in the long run. ${ }^{8}$

[Figure 2 about here.]

In terms of Figure 2, both neoclassical and widow's cruse models share a similar point of view. Their $\pi(u)$ schedule has a shallow positive slope, cutting

\footnotetext{
${ }^{6}$ Investment could also depend on $\mathrm{u}$ directly in a version of the accelerator, but we leave that out for simplicity. It makes profit-led demand less likely.

${ }^{7}$ With $\pi$ on the vertical axis, the shift northwest from $F$ to $G$ is consistent with a southwest move in Figure 1.

${ }^{8}$ As discussed below, households in the top one percent provide around $60 \%$ of private saving in the USA. A shift in the income distribution in their favor can significantly reduce the multiplier.
} 
the effective demand $u(\pi, Z)$ curve from the left. An increase in aggregate demand shifts $u(\pi, Z)$ up (to the right), so $u, \pi$, and $r=\pi u$ all increase. As described above, such a profit boost or wage squeeze when aggregate demand rises is not observed in the data. We can do better by treating $u, r$, and $\hat{K}$ as being determined by $\pi$ and $Z$. To do so, we have to bring in dynamics of $Z$.

\section{$6 \quad$ Steady states}

Following Pasinetti, the growth rate of capitalists' capital is

$$
\hat{K}_{c}=s_{c} \pi u-\delta
$$

Pasinetti concentrated on properties of the steady state, but the focus here is on dynamics of growth. The concentration ratio $Z$ may converge to a steady state at which $\hat{K}_{c}=\hat{K}=\bar{g}$. The growth rate $\bar{g}$ is endogenous in the present model, while both Piketty and Pasinetti treat it as exogenous, perhaps determined from the supply side. Either way, we can restate equation (8a) as an extension of a famous formula due to Pasinetti, ${ }^{9}$

$$
s_{c} r-\delta=\bar{g}
$$

For a given $\bar{g}$, the profit rate will be higher, the lower is the capitalist saving rate $s_{c}-$ a manifestation of the widow's cruse.

To analyze macro dynamics, with $\hat{Z}=\hat{K}_{c}-\hat{K}$ we can use equations (4) and (8a) to get a differential equation for $Z$,

$$
\dot{Z}=\left[\left[s_{c}(1-Z)+s_{w} Z\right] \pi-s_{w}\right] Z u
$$

subject to the restrictions equations (6) and (7). The question at hand is whether $Z$ will converge toward a steady state with $\dot{Z}=0$ and $\hat{K}_{c}=\hat{K}$.

More compact equations are easier to work with. Let

$$
f(Z)=\left[s_{c}(1-Z)+s_{w} Z\right] \pi-s_{w}
$$

\footnotetext{
${ }^{9}$ Piketty emphasizes a neoclassical explanation for wealth concentration relying on the inequality $r>g$. With $s_{c}<1$ and $\delta>0$, equation (8b) already shows that this condition holds at steady state, regardless of neoclassical theory.
} 


$$
=\left(s_{c} \pi-s_{w}\right)-\left(s_{c}-s_{w}\right) \pi Z
$$

For future reference the derivative of $f$ is

$$
d f / d Z=f^{\prime}=\left[-\left(s_{c}-s_{w}\right) \pi+\left[s_{c}(1-Z)+s_{w} Z\right] \pi^{\prime}\right]
$$

in which $\pi^{\prime}=d \pi / d Z>0$ from Figure 2. From the same source we also have $u^{\prime}<0$. Note that $f^{\prime}$ can take either sign. The second derivative is

$$
f^{\prime \prime}=\left[-2\left(s_{c}-s_{w}\right) \pi^{\prime}+\left[s_{c}(1-Z)+s_{w} Z\right] \pi^{\prime \prime}\right]
$$

which we will assume to be negative (that is, $\pi^{\prime \prime}=\frac{d \pi^{2}}{d Z^{2}}$ is not strongly positive).

With this notation we have

$$
\dot{Z}=f Z u
$$

and

$$
d \dot{Z} / d Z=Z\left[f^{\prime} u+f u^{\prime}\right]+f u .
$$

Equation (9) or (12) permits several steady state solutions with $\dot{Z}=0$ to exist. One can describe them in terms of the profit share response parameter $\pi^{\prime}$ and the capitalist saving rate $s_{c}$. Pasinetti concentrated on a steady state with $0<Z<1$, illustrated in Figure 3. There can be a stable Pasinetti equilibrium at point $P$, with $f(Z)=0$ and $d \dot{Z} / d Z=f^{\prime} Z u$ from equation (13). With a low relatively low value of $\pi^{\prime}, f^{\prime}<0$ from equation (11) so the equilibrium is stable. Also, $d r / d Z<0$ and the capital stock growth rate $\hat{K}$ is a decreasing function of $Z$ from equation (5). ${ }^{10}$

[Figure 3 about here.]

\footnotetext{
${ }^{10}$ There can also be a "dual" equilibrium at $Z=0$, labeled $S M$ after a paper by Paul Samuelson and Franco Modigliani (1966). It resembles Piketty's set-up when $s_{c}=s_{w}=s$ and there is no class distinction in saving rates. The shift of equilibrium from $S M$ to $P$ is an example of a saddle-node or transcritical bifurcation of the differential equation (9) or (12) there is a regime change parameterized by the rentier saving rate $s_{c}$.
} 


\section{Capital and income in the long run}

What happens to the concentration ratio $Z$ in steady state? To a large extent, steady growth is "supply constrained" insofar as all stocks and flows must increase at the same rate. In the medium run, $\pi$ and $u$ determine investment and the rate of growth $g$. Because $g$ is constant at a steady state, it sets the levels of these and other variables.

At the Pasinetti solution (ignoring depreciation for simplicity), "flow-stock" ratios must equalize across comparable variables. Say's Law applies and the paradox of thrift is nullified in the "long run" (if we ever get there).

Specifically, if $S_{w}$ and $S_{c}$ are savings flows of workers and capitalists and $S$ is total saving then it must be true that $S_{w} / K_{w}=S_{c} / K_{c}=S / K=\hat{K}=g$

We can parameterize these relationships using lower case $s_{w}$ and $s_{c}$ for saving rates, letting $W=(1-\pi) X$ be the wage bill, and noting that $K_{w}=K-K_{c}$. Then these equations can be restated as

$$
s_{w}\left[r\left(K-K_{c}\right)+W\right] /\left(K-K_{c}\right)=s_{c} r K_{c} / K_{c}=g .
$$

A version of Pasinetti's formula:

$$
g=s_{c} r
$$

follows immediately. The profit rate adjusts to changes in $s_{c}$ and $g$.

More interesting is that fact that the capital concentration ratio adjusts as well. One can use equation (14) to derive

$$
s_{w} r+s_{w} W /\left(K-K_{c}\right)=s_{c} r .
$$

Since $K-K_{c}=K(1-Z)$ we get

$$
1-Z=\left[s_{w} /\left(s_{c}-s_{w}\right)\right](W / r K)=\left[s_{w} /\left(s_{c}-s_{w}\right)\right][(1-\pi) / \pi] .
$$

Shares of wealth in the long run are intimately related to the distribution of income between profits and wages, and thereby social change and redistributive policy. The workers' share of capital, $1-Z$, increases with $s_{w}$ and decreases 
with $s_{c}$ and $\pi$. The former effect reflects the observation of James Meade (1964) in that wages are a potential source of savings unavailable to rentiers, setting an upper limit to $Z .{ }^{11}$ A corollary is that because of their different sources of income both classes will co-exist in steady state, contrary to neoclassical models such as one by Joseph Stiglitz (2014) in which income sources are blended and the highest saving group takes over all wealth.

Although it only applies at a steady state, equation (15) points to another aspect of the accumulation process. At any time, there is a given stock of capital which has to be held by either capitalists or workers. Because $s_{c}>s_{w}$ the former have the upper hand in accumulating wealth. This observation is consistent with Mellon's views about the "rightful owners" of assets - they have a lot of money and save a lot.

The power of owners historically has been constrained by public or societal interventions such as direct taxation, imposed income redistribution, levies on capital, and confiscation or morally sanctioned renunciation of wealth as under Islam. Charles Lindblom (1977) famously observed that the state in principle, although constrained in practice, can always use its powers of coercion to seize capital and save or invest the proceeds for its own purposes, as will be illustrated later. But it would need to have an ownership and investment vehicle on hand.

\section{Income, wealth, and capital gains}

As noted above, Pasinetti $(1962,1974)$; Piketty (2014) presume that households get direct access to all profits $r K=\pi X$. Available data do not fit the hypothesis. In the national accounts households receive financial transfers $F$ (interest and dividends ) while the corporate business sector has (usually positive) saving $S_{b}$. In the data $\pi X \approx F+S_{b}$ (minor discrepancies arise due to transfers outside the financial sector). How can households get their hands on

\footnotetext{
${ }^{11}$ Meade's argument shows why $Z$ will not rise to a value of one. Even so, the upper bound may be high. Plausible numbers are $s_{c}=0.5, s_{w}=0.1$, and $\pi=0.4$. These numbers generate a steady state value for $Z$ of 0.625 , in the range reported by the simulation model below.
} 
$S_{b}$ ? The answer is capital gains.

To pursue the details, simple macroeconomic accounting is helpful. We begin with the income and product accounts and proceed to flows of funds and balance sheets. Figure 4 lays out a social accounting matrix for an economy without government, foreign trade, and (for the moment) depreciation.

[Figure 4 about here.]

The key accounting convention is that sums of corresponding row and columns should be equal. There are still two classes (the number will grow to three in the simulations presented later). All households receive income from various sources, so we replace the worker and capitalist labels with "middle income" and "rich." There is a goods-producing business sector, and "finance" which receives interest and dividend payments from business and distributes them (without incurring costs) to households. ${ }^{12}$

The first row gives the decomposition of output $X$ into consumption and gross investment; the first column is a breakdown of costs. Middle-income households receive labor payments $\psi_{m} X$ from business and transfers $F_{m}$ from finance to give income $Y_{m}=\psi_{m} X+F_{m}$. In the corresponding column they consume $C_{m}$ and save $S_{m}$ in the row for "macro balance." The accounting for rich households with income $Y_{r}$ is similar. After paying labor, business has gross profits $\pi X$. A portion $F_{b}=F_{m}+F_{r}$ is transferred to finance for distribution to households; the rest is saved as $S_{b}$. The macro balance row states that total saving equals investment. Substitution among the entries shows that

$$
\pi X=F_{b}+S_{b}
$$

exactly. Profits are exhausted by financial transfers and business saving. ${ }^{13}$ The transfers all flow to households.

\footnotetext{
${ }^{12}$ This treatment of finance approximates the set-up of the US national accounts.

${ }^{13}$ In SAMs based on US data, the equality of profits to financial transfers plus business saving holds to about three significant digits.
} 


\section{Rents and Capital Gains}

Piketty and Stiglitz emphasize that increases in asset valuations have contributed to the concentration of wealth. One mechanism can be capitalization of "rent," a tricky concept. Tracing back beyond Adam Smith, rent can be viewed as payment for the use of some asset; in other words it is a monopoly price. ${ }^{14}$ Along Lindblom's lines the threat of coercion (legally sanctioned or otherwise) underlies a monopoly position. Rents and "rent-seeking" (Krueger, 1974) are a vehicle for mainstream economists to bring class and power into discussion.

Rent-seeking interprets some rents as claims on income associated with social relationships which do not themselves create income. For example a firm bribes politicians to get legislation increasing its profits. ${ }^{15}$ This version was popularized by Gordon Tullock (1967). Even he, however, emphasized difficulties in quantifying rent-creating claims. Krueger ran the research department of the World Bank in the 1980s. It devoted a lot of effort toward putting numbers on rents in developing countries, with shaky results.

Stiglitz points to rents, legitimate or not, as sources of wealth inequality if they are "capitalized." That is if some rental flow $\rho$ is associated with the stock of an asset and there is a perfect capital market for the asset in question, then its value will be $\rho / i$ with $i$ as the relevant interest rate. Capitalization of (say) urban rents or subsidies to Texas cotton growers can give high valuations to the associated buildings or land. Like Tullock and Krueger he provides little guidance about the magnitude of these asset prices. Nor is it clear how the capital gains involved make their way from business accounts to households.

A more direct route is to ask how households can access the income embodied in gross business saving, which in the USA fluctuates in the range of $\$ 1.5$ trillion (roughly ten percent of GDP) per year. Realized capital gains on eq-

\footnotetext{
${ }^{14}$ Duncan Foley (2006) provides a lucid analysis of the economics of rent over the centuries since Smith.

${ }^{15}$ Which relationships generate income is another tricky question. Import quotas are legally sanctioned public-private relationships often used to exemplify targets of rent-seeking. But they helped stimulate industrialization in Korea, so were they unproductive?
} 
uity and the stock of residential housing are observable and can function as the transmission mechanism by increasing asset values. ${ }^{16}$ We can quickly demonstrate the accounting in connection with simplified (omitting money and bonds) balance sheets in Figure 5 .

[Figure 5 about here.]

The term $E$ stands for equity outstanding (treated as a liability of business) at price $P_{e}$. Besides equity, households hold capital $K_{h}$ (residential housing). Their saving is $S_{h}$, wealth is $\Omega_{h}$, and debt is $D_{h}$. Let a "dot" over a variable represent its change over time and a "hat" its growth rate. The household flow of funds can be written as

$$
S_{h}+\dot{D}_{h}=I_{h}+P_{e} \dot{E}
$$

i.e. saving plus new debt finance residential investment plus purchases of newly issued equity at the going price. A negative value of $\dot{D}_{h}$ would represent new net lending by households, for example to the banking system in the form of higher deposits. Share buybacks imply that $\dot{E}<0$, presumably accompanied by an rise in $P_{e}$.

The increase in capital is

$$
\dot{K}_{h}=I_{h}-\delta_{h} K_{h}
$$

with $\delta_{h}$ as a rate of depreciation.

"Differentiating the balance sheet" in Figure 5 gives

$$
\dot{\Omega}_{h}=\dot{P}_{e} E+P_{e} \dot{E}+I_{h}-\delta_{h} K_{h}-\dot{D}_{h} .
$$

\footnotetext{
${ }^{16}$ This point has been recognized for a long time, and is built into a perfect foresight equation for capital gains proposed by Myron Gordon (1959). Using notation introduced immediately below, let the dividend/capital stock ratio be $\Delta$ and $q=\left(P_{e} E\right) / K$. Then the Gordon equation (ignoring returns to bonds, taxation, and other complications) becomes $r=\hat{P}_{e}+\Delta / q$, or profits are exhausted by dividends and capital gains on equity. The formula is not rejected by the data.
} 
Substitution from the flow of funds then shows that

$$
\dot{\Omega}_{h}=S_{h}-\delta_{h} K_{h}+\dot{P}_{e} E
$$

An increase in household wealth is generated by net saving and capital gains.

Households' increases in $P_{e}$ are losses for business so the corresponding expression is

$$
\dot{\Omega}_{b}=S_{b}-\delta_{b} K_{b}-\dot{P}_{e} E
$$

with $S_{b}$ as profits minus interest, dividends, direct taxes, etc.

The empirical question at hand from equation (19) is how net business saving $S_{b}-\delta_{b} K_{b}$ compares to capital losses $-\dot{P}_{e} E$ due to rising prices of equity. Figure 6 presents data on all realized capital gains (including residential housing) since the mid-1980s. On the whole, yearly gains by households are greater than net business saving so $\dot{\Omega}_{b}<0$. Sums exceeding profits are transferred to households via financial flows and asset price changes, running down firms' net worth.

[Figure 6 about here.]

What forces cause capital gains is a vexed and open issue. Capitalization may enter the process by driving up property valuations which get channeled to owner households. Low interest rates beginning in the mid-2000s contributed. A more fundamental factor is the corporate governance philosophy of maximizing shareholder value (and one might add the strategy of executives paid in the form of stock options to prop their payments up). One manifestation is the movement toward share buybacks, which may reach a trillion dollars in 2015.

For future reference, finally note that income as defined in terms of the Figure 4 SAM, does not include capital gains (the "Haig-Simons" definition of income does not apply). Rather, they enter into changes in wealth as defined in equations (18) and (19). As illustrated below, a tax on capital gains thereby has different macroeconomic impacts than, say, a tax on interest or dividends. 


\section{Incomes and wealth}

Now it is time to look at the numbers, to see if theory can be adjusted to data so that it can be used to say something about US distributive prospects.

\subsection{Income flows to the classes}

The Congressional Budget Office (CBO, 2012) presents estimates of income from different sources for groups of households all across the distribution, from 1986 through 2011. We rescaled the CBO numbers (including capital gains) to be consistent with the national income and product accounts, to give insight into their macroeconomic significance. ${ }^{17}$ Here we work with a three-class breakdown, treating the top one percent as rich, the group between the $60^{\text {th }}$ and $99^{\text {th }}$ percentiles as middle income, and the rest as lower income.

Look first at households in the top one percent of the income size distribution. These people generate most household saving and hold substantial wealth, including equity which produces capital gains. Figure 7 summarizes their mean income levels per household over time - late in the decade it was more than $\$ 2$ million per year. The green segments toward the bottom of the bars show that the well-off did receive growing pre-tax income from labor compensation, around seven percent of the total economy-wide. Bigger chunks come from interest and dividends along with rents and proprietors' incomes like lawyers' fees. Capital gains were substantial in many years.

[Figure 7 about here.]

The chart indicates that rich households steadily gained income from all sources. Over two decades their share of the household total rose by around $10 \%$ - a very large change for such an indicator. After Federal taxes, income disparities remain large. The top one percent pay somewhat higher overall rates (23\% of pre-tax income as opposed to $18 \%$ for all households). Their

\footnotetext{
${ }^{17}$ For details, see Taylor et al. (2014).
} 
direct taxes are more progressive but they are scarcely touched by regressive FICA employment taxes. ${ }^{18}$

In 2011 there were 1.1 million households in the top one percent with a mean pre-tax income of $\$ 2.073$ million, not including capital gains, for a total of $\$ 2.28$ trillion. GDP was $\$ 15.52$ trillion so the top group absorbed $14.7 \%$ of total output. Including capital gains, in 2014 they probably got close to three trillion. Fifteen percent of GDP represents enormous economic power.

Figure 8 shows middle class income sources which sum to $55 \%$ of the total. Note the difference in the scales between Figures 7 and 8. The top one percent's income is factor of ten higher than the middle class's. It simply does not fit with flows to the other $99 \%$ of households.

[Figure 8 about here.]

Middle class mean income is around $\$ 160,000$. These households have positive saving rates and visible net worth, largely concentrated in housing. Labor compensation makes up almost $70 \%$ of their income and $65 \%$ of the total across all three classes. The pre-tax level increased from around $\$ 95,000$ per household in 1986 to $\$ 110,000$ in 2011 - a modest growth rate of half a percent per year. In the USA, a visible share of labor pay is absorbed by FICA, explaining the $21 \%$ tax rate that these households pay (their direct tax rate is $10.5 \%$ ).

Other significant income sources are interest and dividends, proprietors' incomes and government transfers such as Social Security, Medicare, unemployment insurance, and (at lower income levels) food stamps and Medicaid.

Figure 9 shows that households in the bottom $60 \%$ are highly dependent on labor income for their mean level of $\$ 55,000$. In 2011 , transfers were around two-thirds of wages. In reported consumer expenditure data, this group has a negative savings rate, meaning that people spend more than they receive. Their average wealth is close to zero, so that financial incomes are very small.

\footnotetext{
${ }^{18}$ One might add that Federal income tax rates decline at the highest income levels, e.g.17.6 percent for the richest 0.001 percent of households with average "adjusted gross income" from their tax forms exceeding $\$ 60$ million per year.
} 
[Figure 9 about here.]

\subsection{Distribution of wealth}

Figure 10 presents a snapshot of the US distribution of wealth in 2012, based on the Federal Reserve's Financial Accounts and Edward Wolff's breakdown of the size distribution of holdings which comprise physical capital, the value of equity, and other financial instruments ("bonds"). Assets held by each group of actors have a negative sign; liabilities and net worth are positive. The numbers don't add up -reported holdings of bonds by households and finance exceed the supply from firms, government, and the rest of the world.

[Figure 10 about here.]

In any case, consistent with the data on flows in Figure 6, the business sector has negative net worth. As noted above, the value of equity outstanding $(\$ 29,483$ trillion) substantially exceeds firms' capital stock ( $\$ 19,903$ trillion).

In contrast to growth models, total wealth of the private sector - households (and nonprofit institutions) and business combined - includes financial claims besides the value of fixed assets or "capital" $K$. Government debt and net foreign assets both contribute to private net worth. Capital is the dominant entry.

Households in the table are split into the top 1\% and the bottom $99 \%$ of holders of wealth (the $20 \%-80 \%$ split is also included for reference). The top $1 \%$ directly own $35.4 \%$ of household net worth, consistent with other estimates. They hold only $26.9 \%$ of household capital stock, basically residential housing (the top $20 \%$ hold $80.7 \%$ !). Households overall hold roughly one-third of capital, and business holds around one-half. The rest, infrastructure basically, is owned by the government. 


\section{SAM representation}

The next step is to set up a simulation model to track dynamics of wealth accumulation over time. We begin with a quick description of the data base.

Figure 11 is a social accounting matrix illustrating how the three income classes fit into the national economy. The accounting principles are the same as in Figure 4. As noted above, the household size distribution has been rescaled to the national income and product accounts (NIPA). The data refer to 2008, a relatively "normal" year for the US economy as it started to slip into recession.

[Figure 11 about here.]

Several points about the SAM's numbers are worth noting. Total supply in the matrix is $\$ 16848.1$ billion, comprising imports (2556.5) plus GDP (14291.6), as shown in the first column. The first row illustrates how current and capital spending flows break down. Both government and the rest of the world figure in the accounting. Total income flows for the three household groups are 3815.69 (lower), 7504.73 (middle), and 2416.58 (rich).

In the relevant column, transfers (interest and dividends) from the finance sector to households total 2165.4, and in the corresponding row they pay 257.5 to finance. The net transfer is 1907.7. Gross business saving is 1410.1 (in the business expenditure column toward the bottom). In line with equation (16), the financial transfer and saving sum to 3317.8 , close to profits of 3318.3 in the first column.

The top two household groups get the lion's share of financial transfers. The flows are 919.37 to the rich (38\% of their income) and $1029.47(13.7 \%)$ to the middle class. Note that there is also a very large transfer within the business sector, which includes financial firms. That is, business pays out a total of 4416.5 in interest and dividends, and receives 2746.9 back.

To borrow a European phrase, the US economy is a fiscal and financial "transfer union." Net fiscal flows benefit the bottom $60 \%$ of households. They receive 1140.27 in government transfers (almost $30 \%$ of their income) and pay 
slightly negative direct taxes. On the other hand they send 330.22 to the government sector as "social contributions" or FICA and other employment taxes (8.6\% of their income).

At the other end of the distribution, the top one percent get minimal government transfers (15.97) but pay 630.6 (26\% of income) in direct taxes. Their social contributions are minimal at 44.62 .

The middle class pays government more than it receives. Outgoing flows are direct taxes of 853.75 (11.6\% of income) and contributions of $702.16(9.4 \%)$. Incoming transfers are $686.16(9.1 \%)$.

On balance, the bottom $60 \%$ have net inflows from the government sector of 814.1. The middle class have an outflow of 869.75 and the top one percent lay out 614.6. Total transfers to households are 1842.4, or $12.9 \%$ of GDP. In Europe, such flows are on the order of $20 \%$ of GDP.

The bottom rows of the table show saving and investment. The sign convention is that saving is positive and investment negative. The external deficit or "foreign saving" is 683.8 or $4.8 \%$ of GDP. Government saving is -374.6. Public investment represents another outlay of -497.2 so that the overall financial outflow is -871.8 or $6.1 \%$ of GDP. The increase in foreign claims on the US economy is less than new government borrowing so that private sector wealth increases by $871.8-683.8=188$. Private saving from households and business must therefore finance private investment plus the fiscal deficit net of capital inflows or $2087.6+188=2275.6$.

Low income households have negative saving of -1647.4 , or a reported $43.2 \%$ of income. Below-zero saving at the bottom of the size distribution shows up consistently in the Bureau of Economic Analysis consumer expenditure data that we used. ${ }^{19}$ The saving shortfall from low incomes is offset by the middle class (1059.94 or $14.1 \%$ of income) and the rich (1452.56 or $60.1 \%)$. Such large saving differentials suggest that model simulations will in part be driven by

\footnotetext{
${ }^{19}$ One can speculate about what consistently reported negative saving "really" represents. Movements of households' income positions, understated and/or undeclared incomes, and unpaid informal debt are the most obvious explanations.
} 
redistribution across the classes.

\section{Model specification}

In the data, middle and high income households somewhat resemble Pasinetti's abstract workers and capitalists. Minor transfers aside, the main difference is that the rich receive wages and proprietors' incomes along with their interest, dividends, and (in the wealth account) capital gains. Low income households hold only a few percent of total wealth. With their negative saving, they certainly boost effective demand. So in the simulations we track incomes and expenditures for all three classes as well as for business, government, and the rest of the world, but keep track of wealth accumulation only for the upper two classes.

The ratio of wealth held by the rich to the household total (assuming away the modest net worth of the bottom group) becomes a key distributive indicator. To measure income inequality we use "Palma ratios" of disposable incomes per household of the top group to the lower two. Proposed by José Gabriel Palma (2011), these ratios focus attention on income disparities between the classes (as opposed to taking an average across incomes as in a Gini coefficient).

At a given time, macro equilibrium is determined in a simple demand-driven specification. Details of a very similar model are presented in Taylor et al. (2014). Briefly, effective demand is set by household and business investment, government spending, and exports as "injections." The main "leakages" are for taxes net of transfers, imports, and saving. Financial transfers representing interest and dividends shift a portion of total profits to households as in equation (16). The parameter specification makes demand profit-led. The price level $P$ is set as a mark-up on wage and import costs. In equation form we have

$$
P=\left(\Lambda+e a P^{*}\right) /(1-\tau-\Xi-\Pi)
$$

with $\Lambda$ as total labor cost per unit output, eaP* import cost (driven by the exchange rate $e$, import/output coefficient $a$, and world price level $\left.P^{*}\right), \tau$ in- 
direct tax rate, $\Xi$ proprietors' income rate (across household groups), and $\Pi$ the profit mark-up rate. A higher level of economic activity reduces $\Pi$ as discussed above. It is straightforward to solve for output and price variables, with the other entries in the SAM following from accounting relationships. GDP at current prices is $P X-e a P^{*} X$.

Over time, levels of injections, transfers, etc. are scaled to capital stocks or wealth so that the system can grow. Leakages such as taxes and imports are scaled to the level of output. Capital stock growth is governed by equations like (17) for the household classes, business, and government. Real wealth accumulation comes from equation (18) for households and equation (19) for business which must be modified to take a variable price level into account, i.e.

$$
\dot{\Omega}_{h}=\left(S_{h} / P\right)-\delta_{h} K_{h}+\dot{P}_{e} E
$$

and

$$
\dot{\Omega}_{b}=\left(S_{b} / P\right)-\delta_{b} K_{b}-\dot{P}_{e} E
$$

with $S_{h}$ and $S_{b}$ as nominal saving flows.

In the simulations reported here, we set $\dot{P}_{e}$ in each year to drive $\dot{\Omega}_{b}$ to zero, so that all business saving is transferred to households via "capital gains." Profits are $100 \%$ directed to households as in the theoretical literature discussed above. Demand-driven macroeconomic adjustment applies in the model's medium run so that, for example, higher government spending will increase output and the fiscal deficit with multipliers of around 1.7 and 0.7 .

Over time, solutions tend toward a steady state with all variables growing at the same rate. Away from the steady state, distributive changes mix with output adjustment. In the accounting of Figure 11, private saving must finance investment plus the fiscal deficit minus the external deficit on current account. In line with the "Keynesian stability condition" built into model, investment responds less strongly than saving to perturbations so we focus on shifts in the latter. 


\section{Simulation runs}

The simulations aim to examine factors influencing the distributions of income and wealth among the household groups. We begin with an illustrative base run, and go on to variant solutions.

\subsection{Base run and variants}

Figure 12 shows results from a base run of the model (blue curves) and a couple of variants over time. We ran the simulations out to 250 years to illustrate convergence properties of the system (computer time is cheap). Of course only the first few decades are policy-relevant. ${ }^{20}$ The purpose of the base run is to provide a stable benchmark against which distributive variations can be tested. It is not a forecast or projection, and in some ways is unrealistic. ${ }^{21}$ For the moment, potential increases in labor productivity and wage levels are ignored - the economy is zero-sum.

[Figure 12 about here.]

Trajectories of the variables converge toward steady state levels over a century or so, typical of dynamics built around accumulation equations such as (17). Over 50 years, capital utilization $u=X / K$ goes up by about a percentage point, accompanied by decreases in the price level and profit share. Contrary to recent experience the wealth share $Z$ of rich households rises sharply and then settles down at a level of around sixty percent. The modest reductions in $P$ and $\Pi$ are accompanied by slight decreases in the Palma ratios, calculated with respect to disposable income. In short, wealth inequality rises and income inequality stays put.

\footnotetext{
${ }^{20}$ The model was solved over time using Mathematica.

${ }^{21}$ Notably, steady state wealth/output ratios are "too high." The reason is that a high initial level of government net borrowing (6.1\% of GDP) propagates over time, adding to household net worth. We chose not to repair this problem by gradually reducing the deficit/GDP ratio because so doing creates strong fluctuations in solution trajectories for the first few decades.
} 
Government spending over time is proportional to the capital stock. The green curves show what happens when the factor of proportionality is increased by a substantial ten percent. As is to be expected, $u$ increases, leading to profit squeeze reductions in $\Pi$ and $P$. Wealth accumulation is unaffected, with the blue and green curves overlapping for wealth levels $\Omega_{2}$ and $\Omega_{3}$ and the concentration ratio $Z$. The Palma ratios slide down slightly because of the lower mark-up rate.

The orange curves illustrate responses to an increase in the tax rate on high income households by $70 \%$, from about $24 \%$ to $41 \%$. (The level was chosen to have roughly the opposite effect to higher spending.) Overall saving increases (the government's marginal saving or abstinence rate is 100\%) so capital utilization goes down in line with the paradox of thrift. Despite the upper income tax increase, Palma ratios for disposable income increase slightly because reduced output cuts into income flows below the top. Over 50 years, wealth concentration goes down by a few points. The implication of both variants is that relatively large one-shot fiscal adjustments will not have much impact on inequality over time.

\subsection{Capital Gains}

As mentioned above capital gains measured by the growth rate of the price of equity $\hat{P}_{e}$ are supposed to mediate transfers of net business saving to households. Equation (19) describes the mechanism. It is tempting to tax capital gains. Compared to the base run, the effects of a $70 \%$ profits/capital gains tax are shown in Figure 13.

Because the Haig-Simons definition of incomes is not built into the model (see above) the effects of the tax on effective demand and income inequality are minimal. As with the tax on high income households in Figure 12, there are small adjustments in wealth accumulation.

[Figure 13 about here.] 


\subsection{Wages and productivity}

For short, we call mean labor income per household in the three groups "wages." An immediate question is how changes in such payments will affect the macro-economy. Figure 14 shows what happens when the wage of the poor household group is increased by $40 \%$, the middle group gets an increase of $20 \%$, and labor payments per household for the top group are cut by $40 \%$. These changes lie at the extremes of proposals being advanced in 2015 .

[Figure 14 about here.]

Compared to the base run (blue vs. orange), these shifts kick off a big increase in capital utilization via effective demand. The resulting profit squeeze slows investment and the rate of growth. The distribution of wealth shifts against the upper income group but even so the concentration ratio $Z$ tends toward a long-run ratio exceeding one-half. More interesting is that in a growing economy a large once-off shift in labor payments does not strongly affect income inequality - the Palma ratios drop by only a few percent. At least in the present model, static wage adjustments cannot redress unequalizing income trends over the past three decades.

Figure 15 tells a different story. The underlying assumptions are that labor productivity increases over time and that nominal wage levels grow faster. In a bit more detail productivity $\xi$ is assumed to grow at $1.5 \%$ per year initially, with the growth rate tending toward zero as $\xi$ converges toward twice its level in the simulation's base year. Wages are assumed to grow two percent faster than productivity.

[Figure 15 about here.]

There is a pay-off in terms of greater income equality. The Palma ratios decline visibly. Despite favorable wage trends, however, the simulated reductions in the ratios are less than the increases from 11.8 to 33 (lower income) and from 4.3 to 12.7 (middle income) between 1986 and 2008 in our data set. Decreases in wealth concentration are small. 


\subsection{Wealth fund}

As we (and Andrew Mellon) noted at the outset, owners of wealth tend to maintain their positions because their large stocks of assets generate high incomes from which their saving rate is high. The macro economy channels their abstinence into ongoing accumulation.

One way to overcome this advantage is through a public wealth fund which can become an alternative vehicle for accumulation. Perhaps the best-known proposal is still the one put forward 65 years ago by the Swedish trade union economists Gösta Rehn and Rudolf Meidner. Part of the plan involved a fund to be built up from new special shares to be issued by firms which would support workers' pensions. The fund's accumulation would provide a counterweight to private sector saving. ${ }^{22}$ In the recent period, the "oil fund" in Norway ( $\$ 900$ billion in assets) and the California pension fund CalPERS (\$300 billion) provide practical examples of well-known publicly controlled institutions.

We can borrow this idea by imposing a tax on capital gains (by assumption equal to net business profits). But rather than just passing the revenues to the government to be saved uselessly as in Figure 13, they could be transferred to a wealth fund for accumulation. Growing from a zero base, the fund would also receive a share proportional to its size from interest and dividend payments on its investments.

For Meade's reasons the fund would not take over the economy - rich households have income sources besides finance. Nevertheless, the orange curves in Figure 16 shows that with the fund supported by a $70 \%$ tax on capital gains, the share of rich households in total wealth grows for only a few decades and then starts to taper off. The fund's share steadily increases. ${ }^{23}$

\footnotetext{
${ }^{22}$ Blackburn (2005) provides a concise review of the plan. Incidentally, Gösta Rehn was not related to the Finn Swede Olli Rehn, the EU commissioner notorious for his austerian views during the post-2008 financial crisis.

${ }^{23}$ In a Pasinetti world, if there is a tax at rate $t$ on gross profits $r K$ used to finance a wealth fund one can use the logic underlying equation (15) to show that that the fund's steady state share in total wealth would be $s_{f} t / s_{c}(1-t)$, with $s_{f}$ as its saving rate (presumably close to one). If $s_{f}=1$ and $s_{c}=0.5$ then even a $20 \%$ tax on would give the fund ownership of one-half
} 
[Figure 16 about here.]

An obvious question regards the uses of the fund's assets. The Norwegian oil fund, for example, has a target of shifting four percent annually of its assets to the government. In the model here, at least, such a transfer is not feasible in the long run. The wealth fund's share of the total gets up to around ten percent and then steadily declines. The green curves in Figure 16 shows what happens if two percent of fund assets are transferred to government saving and capital formation. The fund's wealth share goes up and then stabilizes while the rich households' share continues to rise. An aggressive public fund appears to be needed to make a real dent in the concentration of wealth.

\section{Bottom Line}

Wage and productivity dynamics on one hand and a wealth fund on the other involve dynamic processes which are largely independent of each other. Figure 17 shows what happens when the two are combined. Income inequality and wealth concentration both go down.

[Figure 17 about here.]

The simulations imply that continuing trends toward equalization over decades would be required if income and wealth inequality is to decline. This result is robust insofar as it mainly is built upon the accounting rules underlying Figures 10 and 11. Policy is relevant only if it can support sustained growth in wages and productivity along with a vehicle to divert abstinence and accumulation toward public ends.

of capital in the long run. 


\section{References}

Barbosa-Filho, N. H. and Taylor, L. (2006). Distributive and demand cycles in the u.s. economy - a structuralist goodwin model. Metroeconomica, 57:389411.

Blackburn, R. (2005). A visionary pragmatist. Retrieved from: www.counterpunch.org/2005/12/22/a-visonary-pragmatist/.

Foley, D. K. (2006). Adam's Fallacy: A Guide to Economic Theology. Belknap Press, Cambridge, MA.

Goodwin, R. M. (1967). A Growth Cycle," in C. H. Feinstein (ed.) Socialism, Capitalism, and Growth. Cambridge University Press, Cambridge, UK.

Gordon, M. J. (1959). Dividends, earnings, and stock prices. Review of Economics and Statistics, 41:99-105.

Kalecki, M. (1971). Selected Essays on the Dynamics of the Capital Economy. Cambridge University Press, Cambridge, UK.

Keynes, J. M. (1930). A Treatise on Money. Macmillan, London.

Keynes, J. M. (1936). The General Theory of Employment, Interest, and Money. Macmillan, London.

Kiefer, D. and Rada, C. (2014). Profit maximising goes global: the race to the bottom. Cambridge Journal of Economics.

Krueger, A. O. (1974). The political economy of the rent-seeking society. American Economic Review, 64:291-303.

Lindblom, C. E. (1977). Politics and Markets: The World's Political-Economic Systems. Basic Books, New York, NY.

Meade, J. E. (1964). Efficiency, Equality, and the Ownership of Property. George Allen \& Unwin, London. 
Palma, J. G. (2011). Homogeneous middle vs. heterogeneous tails and the end of the "inverted u": It's all about the share of the rich. Development and Change, 42:87-153.

Pasinetti, L. L. (1962). Income distribution and rate of profit in relation to the rate of economic growth. Review of Economic Studies, 29:267-279.

Pasinetti, L. L. (1974). The rate of profit in an expanding economy, in Growth and Income Distribution: Essays in Economic Theory. Cambridge University Press, London.

Piketty, T. (2014). Capital in the Twenty-First Century. Belknap Press, Cambridge MA.

Stiglitz, J. E. (2014). New Theoretical Perspectives on the Distribution of Income and Wealth among Individuals. Initiative for Policy Dialog at Columbia University, New York, NY.

Taylor, L., Rezai, A., Kumar, R., and Barbosa, N. (2014). Wage increases, transfers, and the socially determined income distribution in the usa.

Tullock, G. (1967). The welfare costs of tariffs, monopoly, and theft. Western Economic Journal, 5:224-232.

Wolff, E. N. (2012). The asset price meltdown and the wealth of the middle class. NBER Working Paper 18559. 


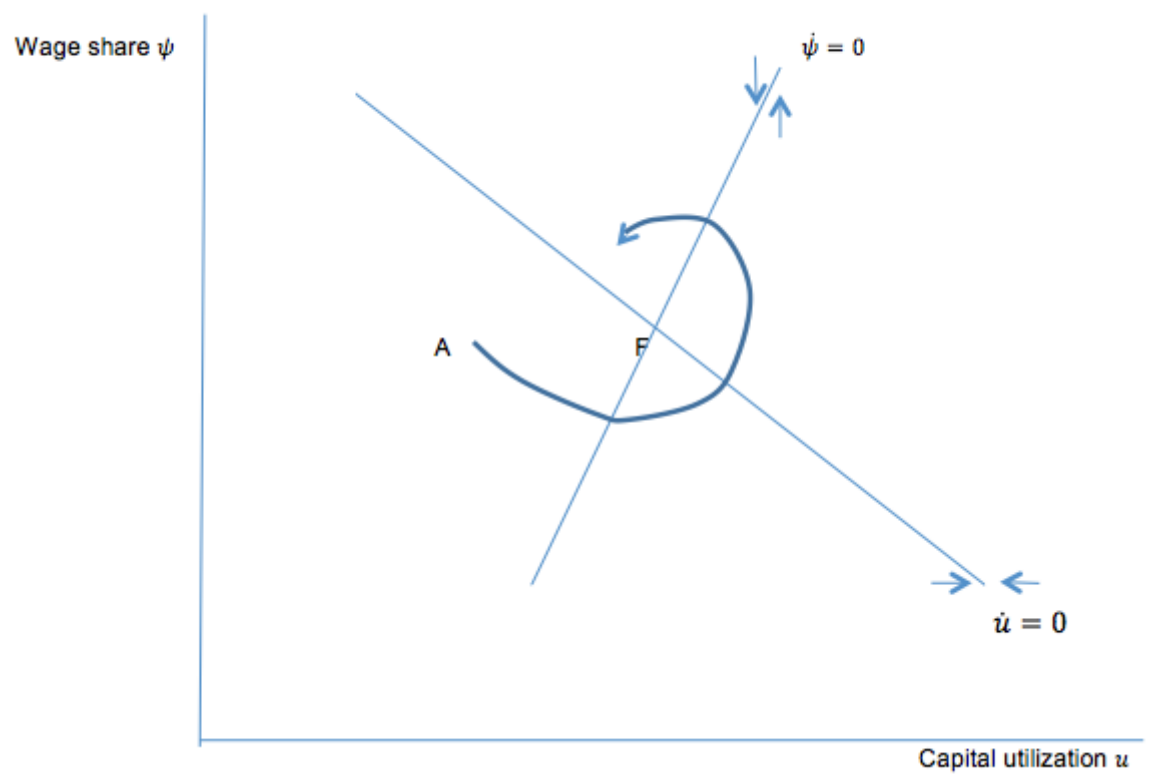

Figure 1: Cyclical dynamics between the wage share $\psi$ and capital utilization $u$. 


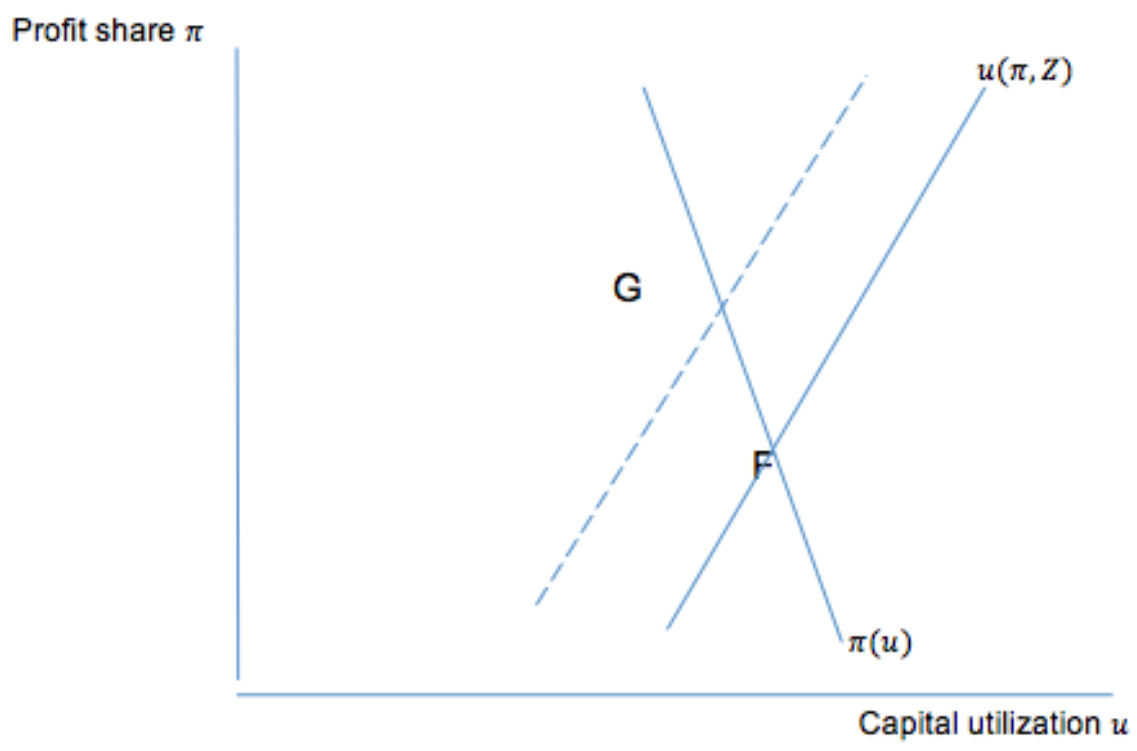

Figure 2: : Determination of the profit share $\pi$ and capital utilization $u$. The dashed line shows the effect of a higher value of the capital control ratio $Z$. 


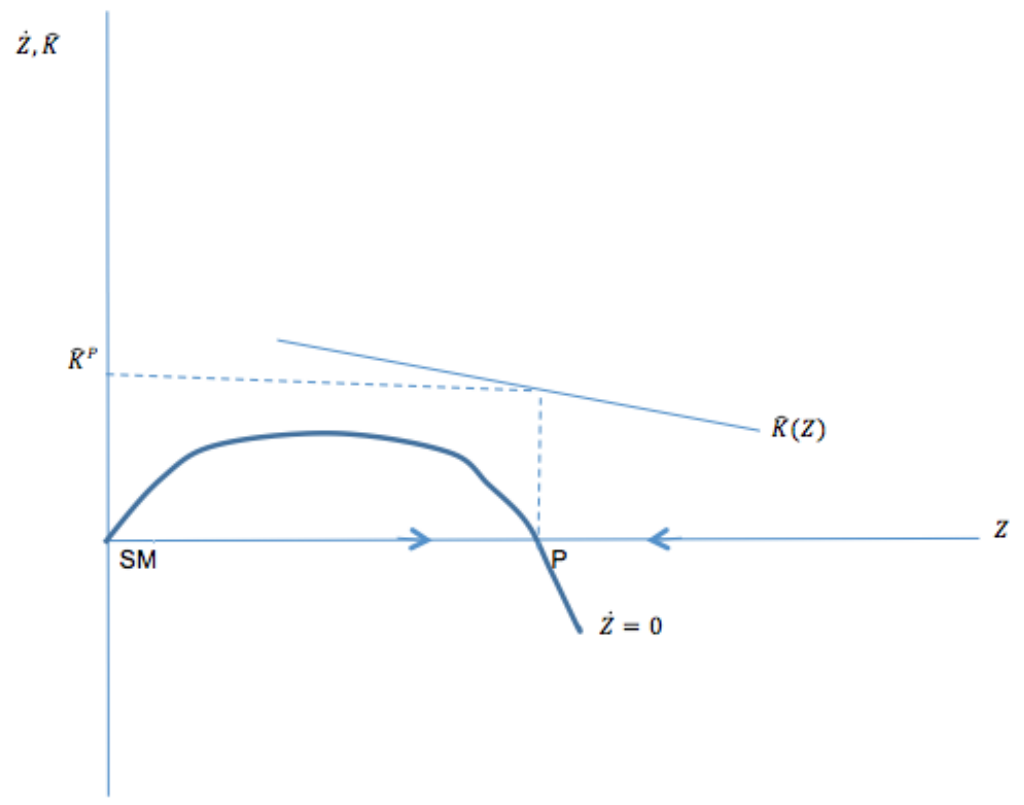

Figure 3: Stable Pasinetti equilibrium at point $P$. The growth rate $\hat{K}$ is a declining function of $Z$ with steady state level $\hat{K}^{P}$ 


\begin{tabular}{|c|c|c|c|c|c|c|c|}
\hline & Costs & & & & & & \\
\hline & & Middle & Rich & Business & $\begin{array}{l}\text { Int. \& } \\
\text { Div. }\end{array}$ & Investment & Totals \\
\hline Outlays & & $C_{m}$ & $C_{r}$ & & & $I$ & $X$ \\
\hline \multicolumn{8}{|l|}{ Middle } \\
\hline Wages & $\psi_{m} X$ & & & & & & $Y_{m}$ \\
\hline Financial & & & & & $F_{m}$ & & \\
\hline & & & & & & & \\
\hline \multicolumn{8}{|l|}{ Rich } \\
\hline Wages & $\psi_{r} X$ & & & & & & $Y_{r}$ \\
\hline Financial & & & & & $F_{r}$ & & \\
\hline \multicolumn{8}{|l|}{ Business } \\
\hline Profits & $\pi X$ & & & & & & $Y_{b}$ \\
\hline & & & & & & & \\
\hline Int. \& Div. & & & & $F_{b}$ & & & $Y_{f}$ \\
\hline $\begin{array}{l}\text { Macro } \\
\text { Balance }\end{array}$ & & $S_{m}$ & $S_{r}$ & $S_{b}$ & 0 & $-I$ & 0 \\
\hline 0 & & & & & & & \\
\hline Totals & $X$ & $Y_{m}$ & $Y_{\tau}$ & $Y_{b}$ & $Y_{f}$ & 0 & \\
\hline
\end{tabular}

Figure 4: Simplified social accounting matrix for economy with "middle" and "rich" classes 


\section{Households}

$P_{e} E \quad D_{h}$

$K_{h} \quad \Omega_{h}$

\section{Business}

$K_{b} \quad P_{e} E$

$D_{b}$

$\Omega_{b}$

Figure 5: Balance sheets for all households and business 


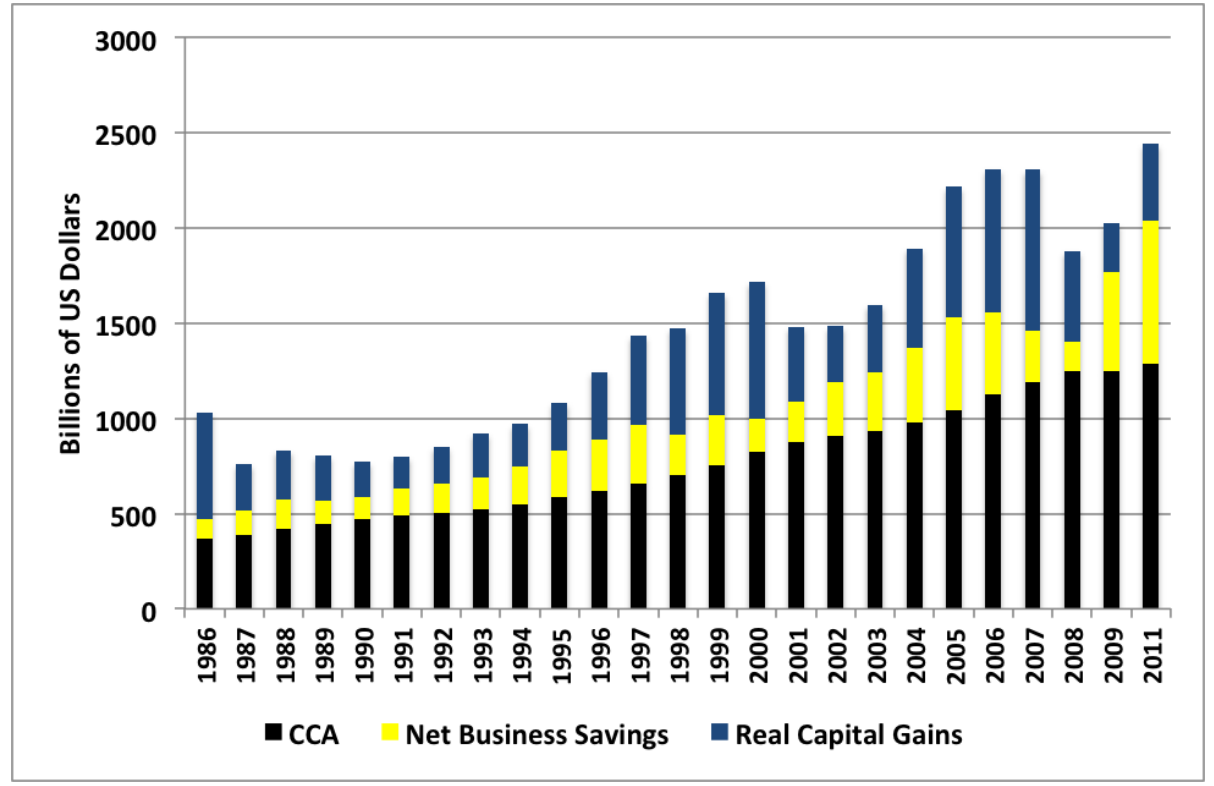

Figure 6: Net business saving, business depreciation, and household capital gains 


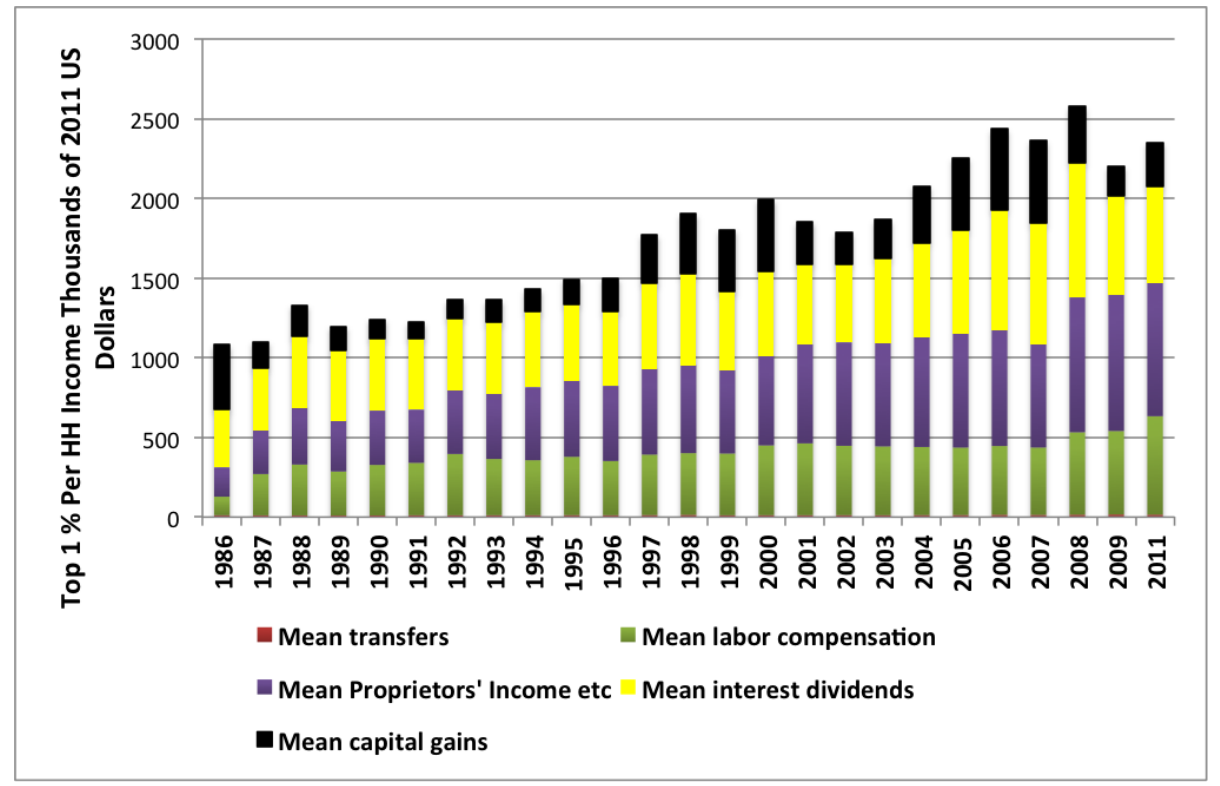

Figure 7: Real per household incomes top 1\% of households 


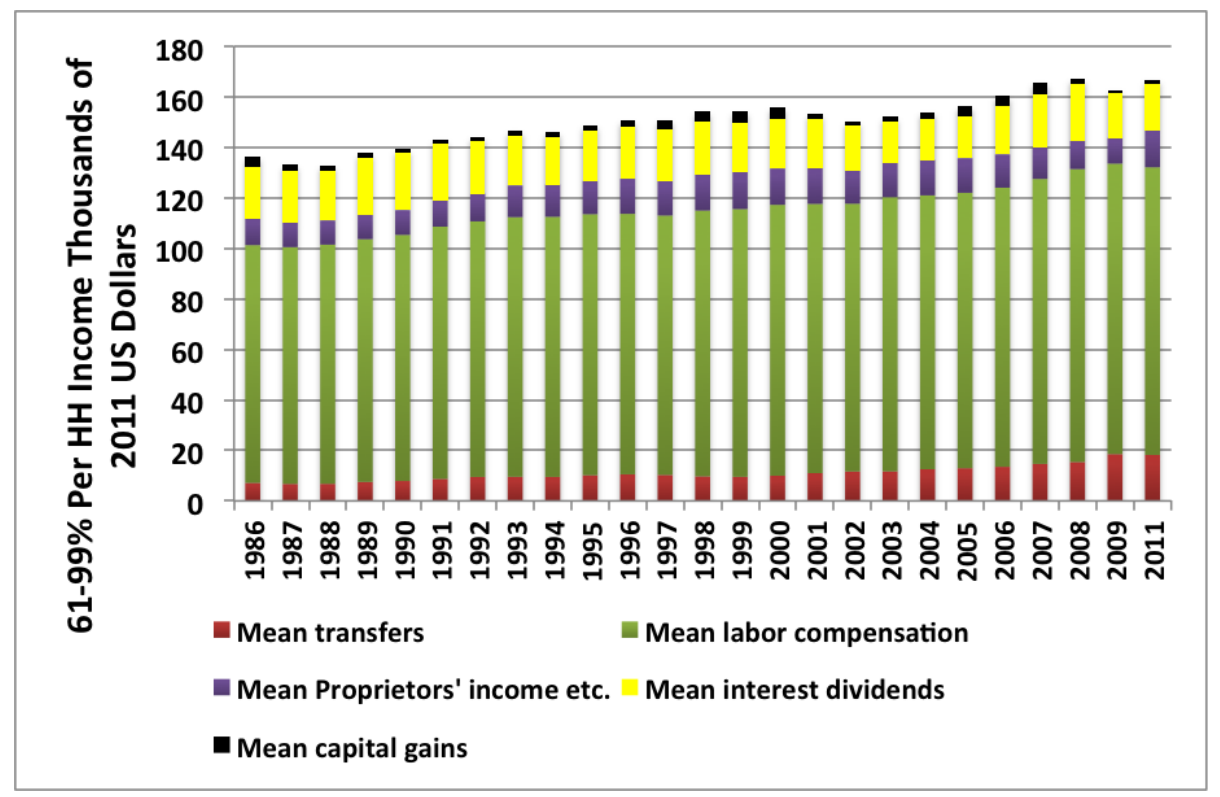

Figure 8: Real per household incomes $61-99 \%$ of households 


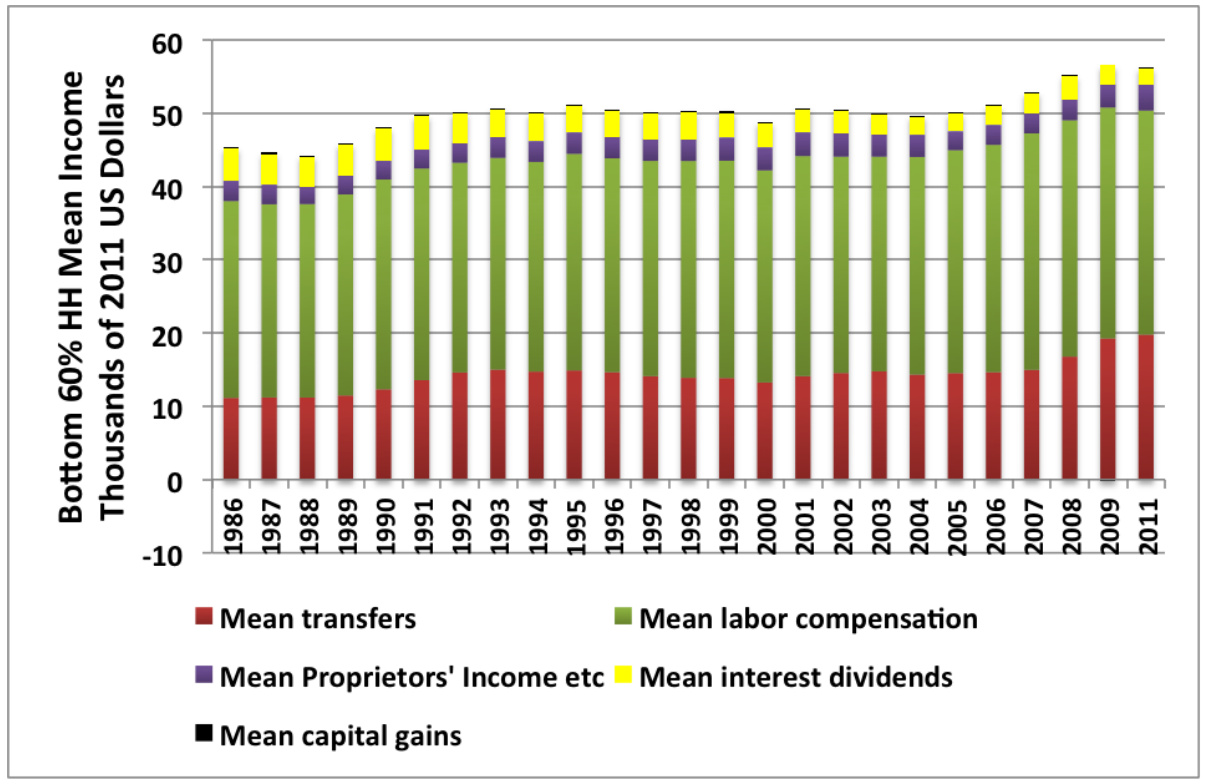

Figure 9: Real per household incomes bottom $60 \%$ of households 


\begin{tabular}{l|cccr} 
& Capital & Bonds & Equity & Net worth \\
\hline All HH & -16312.3 & -23769.1 & -28960.5 & 69041.9 \\
\hline Lower $80 \%$ & -3154.7 & -3176.8 & -1332.2 & 7663.7 \\
Upper 20\% & -13157.6 & -20592.3 & -27628.3 & 61378.2 \\
\hline Lower 99\% & -11923.1 & -15909.8 & -16768.1 & 44601.1 \\
Upper 1\% & -4389.2 & -7859.3 & -12192.4 & 24440.8 \\
\hline Firms & -19903.3 & 1774.7 & 29482.6 & -11354.0 \\
Gov't & -12508.0 & 16862.8 & -279.9 & -4074.9 \\
Finance & & -5131.6 & -1047.2 & 6178.8 \\
R.O.W. & & 3175.3 & 805.1 & -3980.4 \\
\hline Col. sum & -48723.6 & -7087.9 & 0.1 & 55811.4 \\
& & &
\end{tabular}

Figure 10: : US assets (-) vs. liabilities (+) divided into capital stock, bonds and equity, and net worth by sector and household income groups, 2012. Levels in US\$ billions.

Sources: Assets, liabilities, net worth from Financial Accounts (Federal Reserve, 2014); capital stock from Survey of Current Business (October, 2013), household groupings computed based on Wolff (2012). 


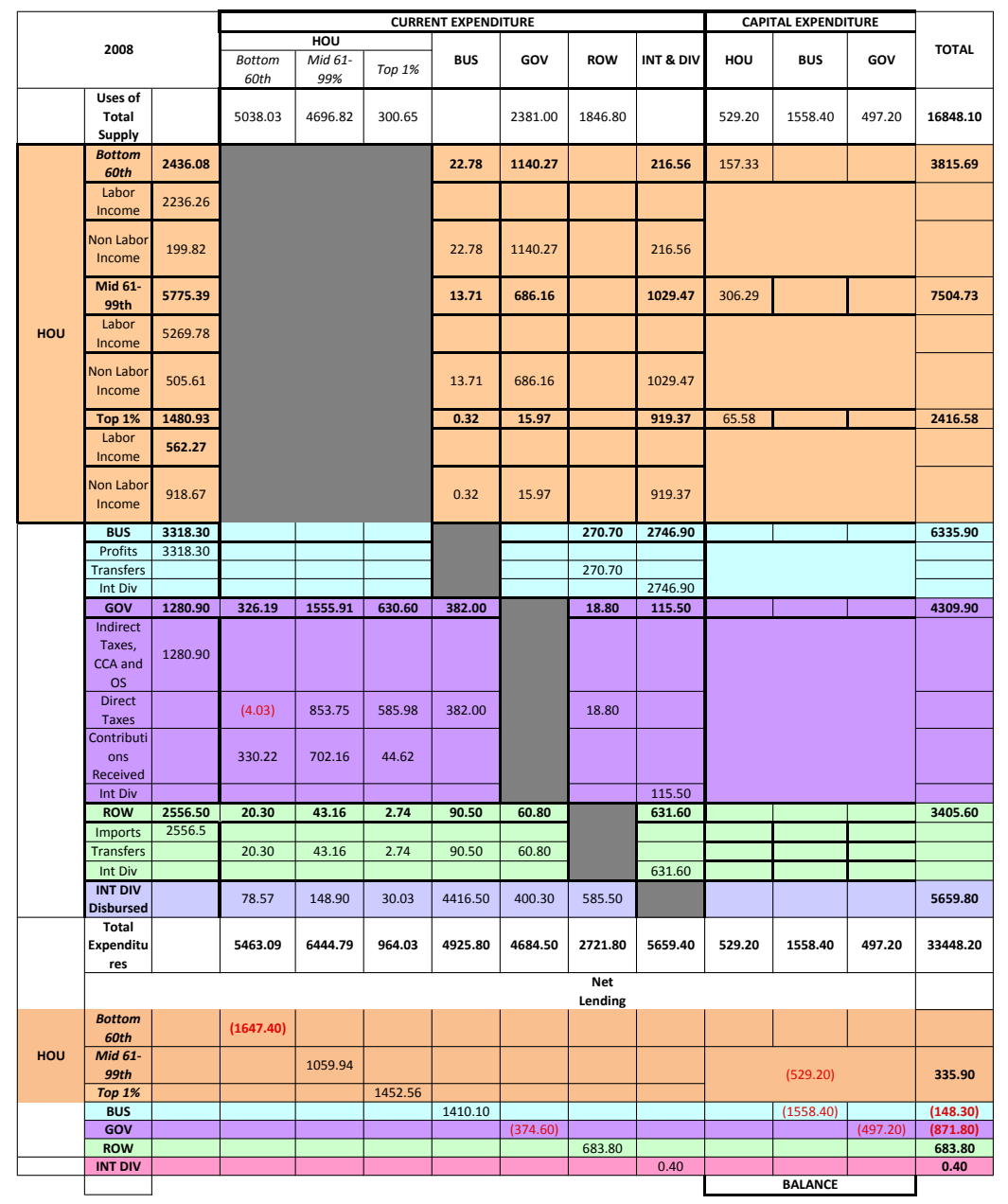

Figure 11: Three-class US social accounting matrix for 2008 

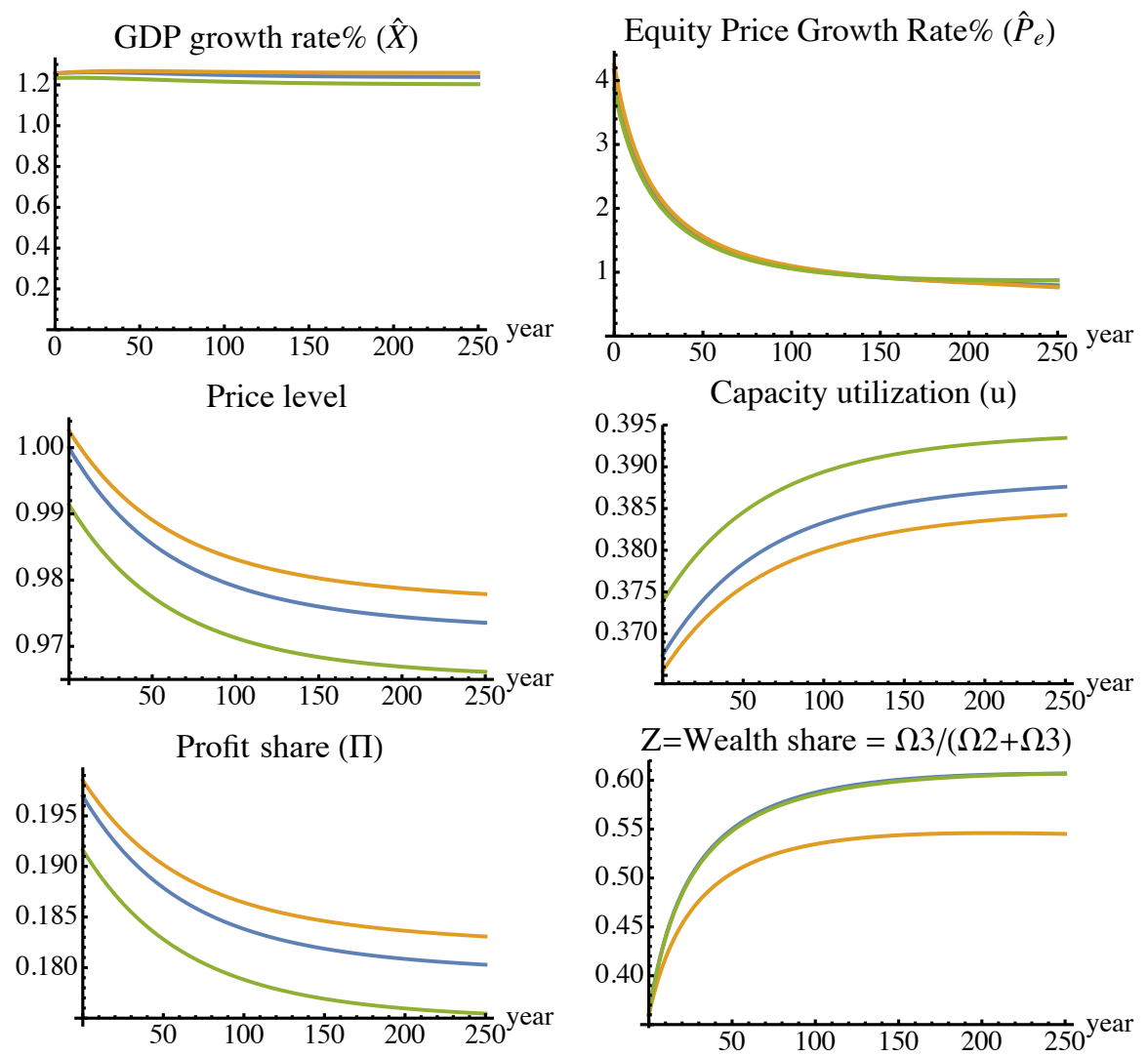

Middle class wealth $(\Omega 2) / G D P$
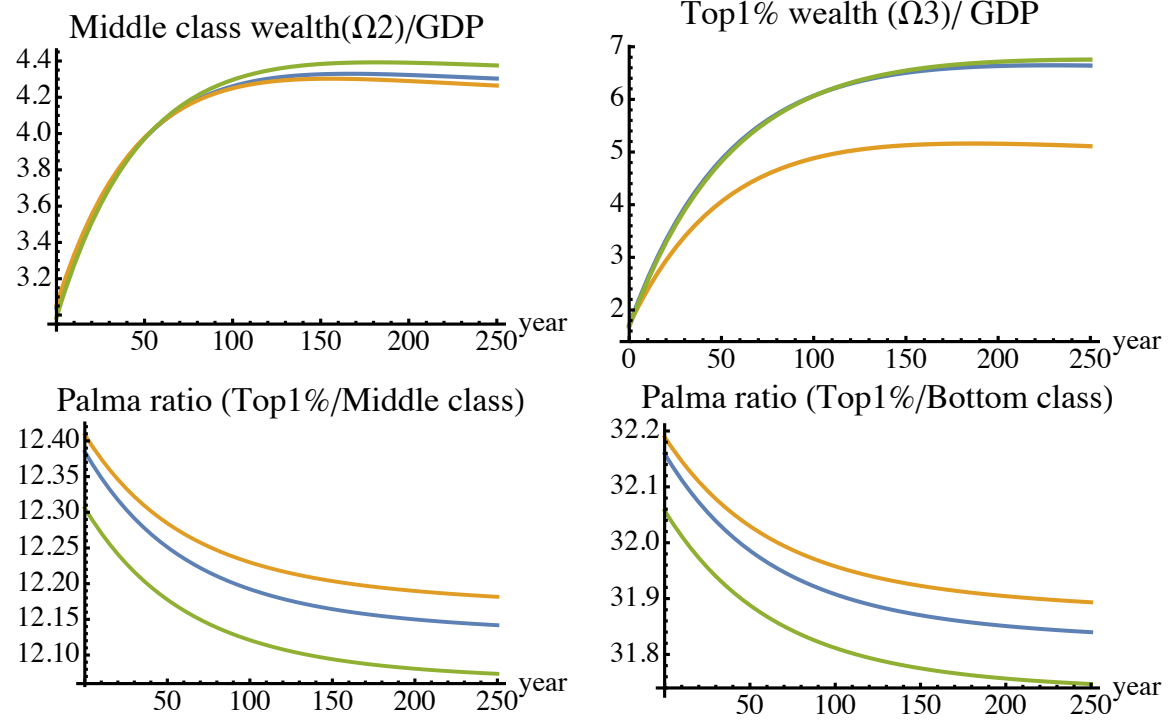

Figure 12: $70 \%$ increase in tax rate on high income households $(\tau)$ is represented by ORANGE, and $10 \%$ increase in government spending $(\mathrm{G})$ represented by GREEN, while BLUE represents the ORIGINAL baseline 

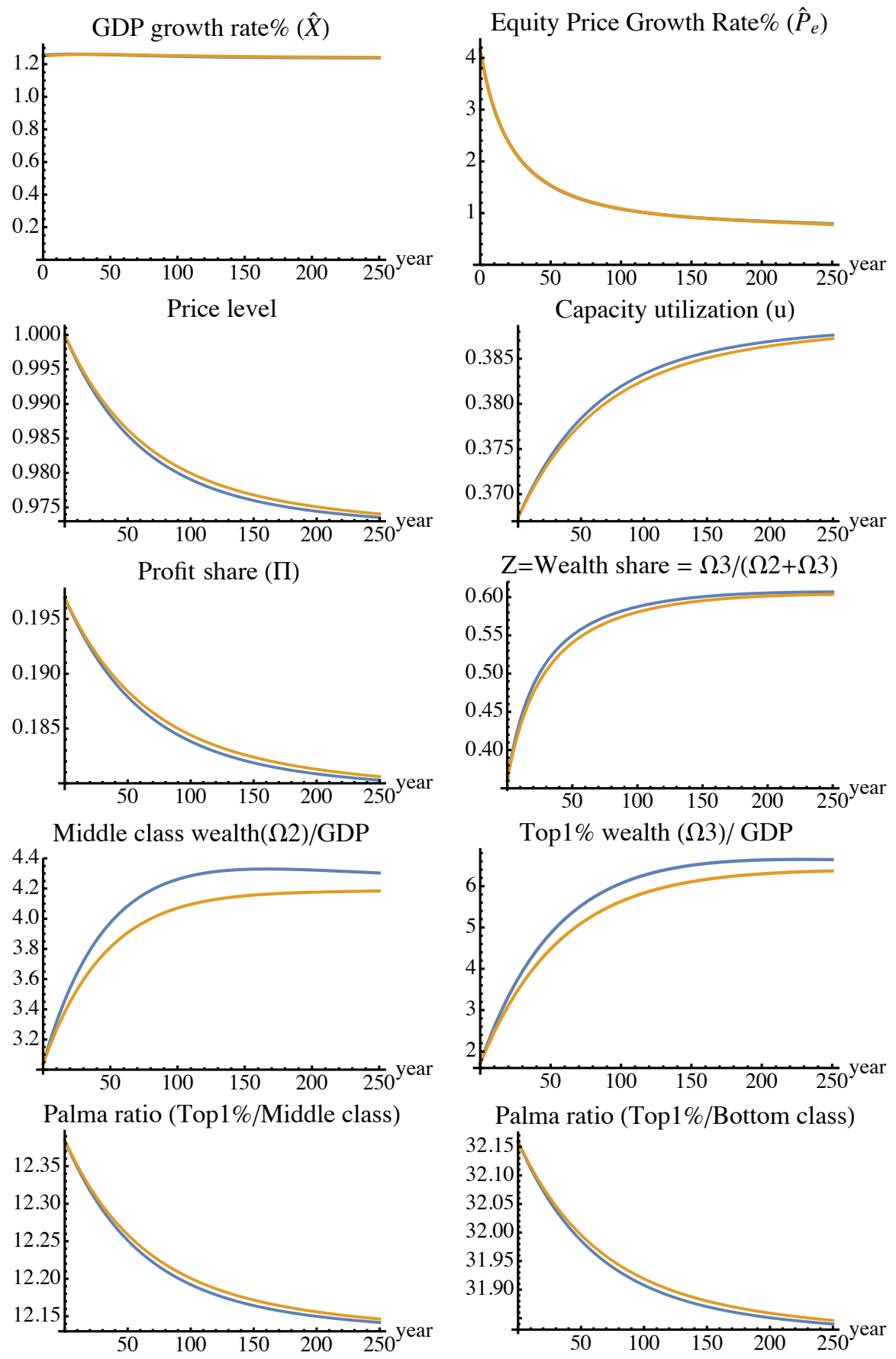

Figure 13: $70 \%$ tax on capital gains for middle and highest income groups, both transferred to government income. Tax on capital gains is represented by ORANGE line while BLUE line represents the original baseline. 

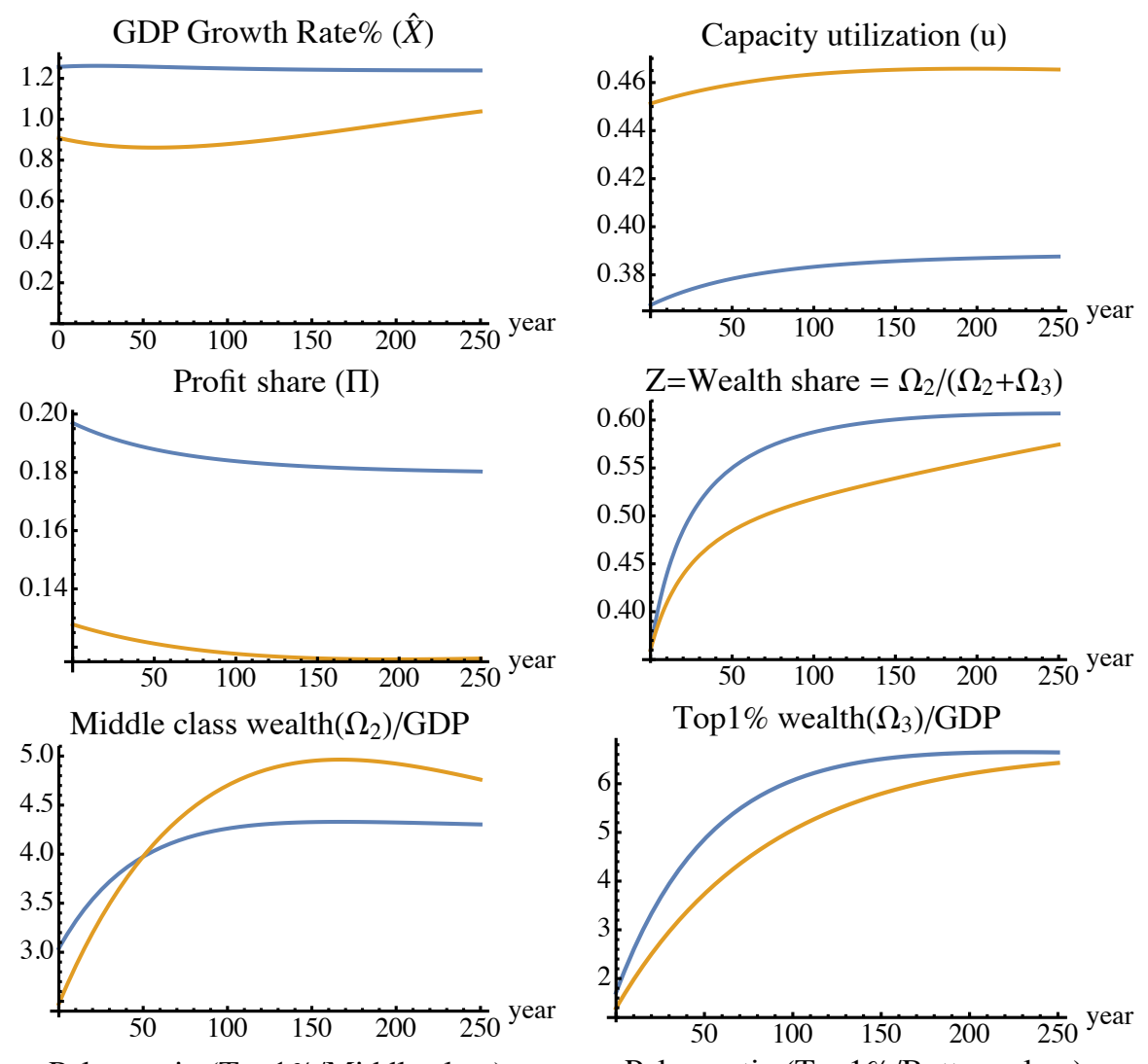

Palma ratio (Top1\%/Middle class)
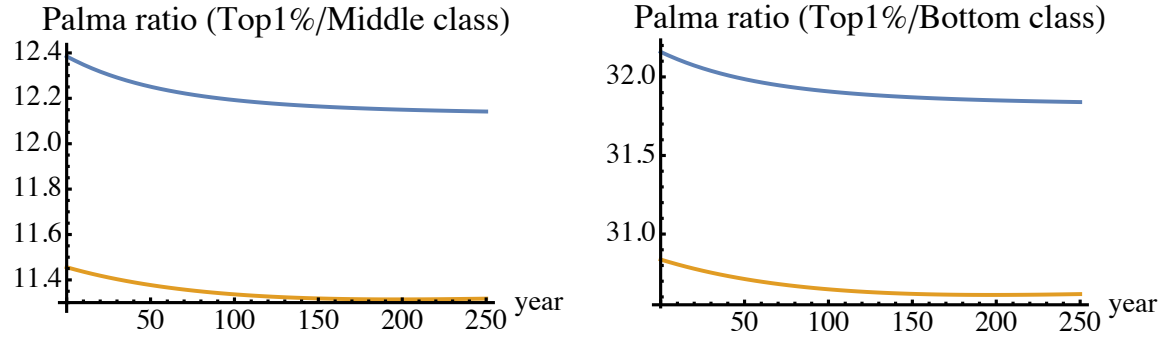

Figure 14: ORANGE line represents wage changes for different income groups. ( $40 \%$ increase for bottom group, $20 \%$ increase for middle group and $40 \%$ decline for top $1 \%$ of households) while baseline is represented by BLUE line. 

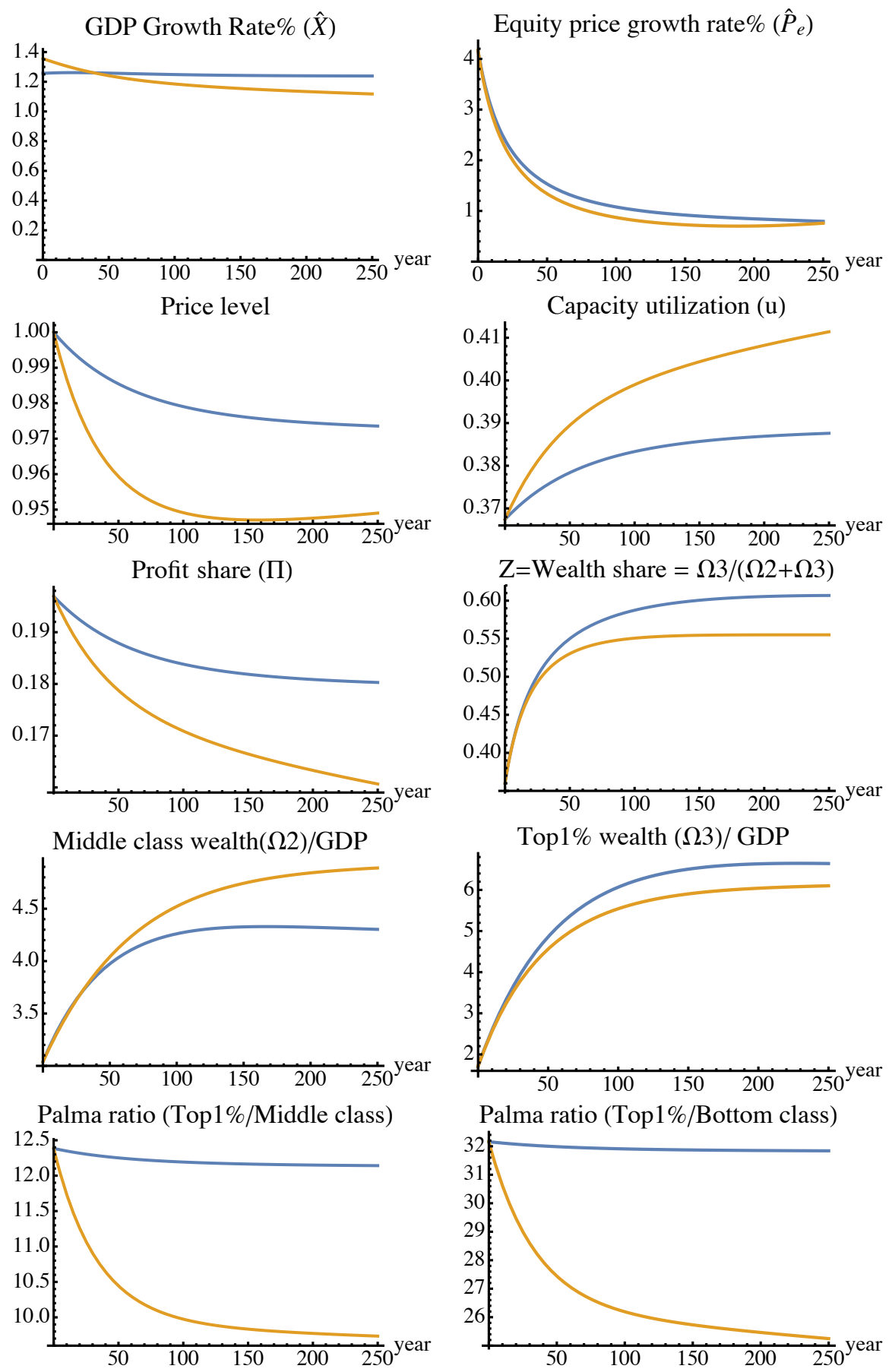

Figure 15: Original baseline (BLUE line) vs labor Baseline with an increase in labor productivity and wage growth (ORANGE line) 

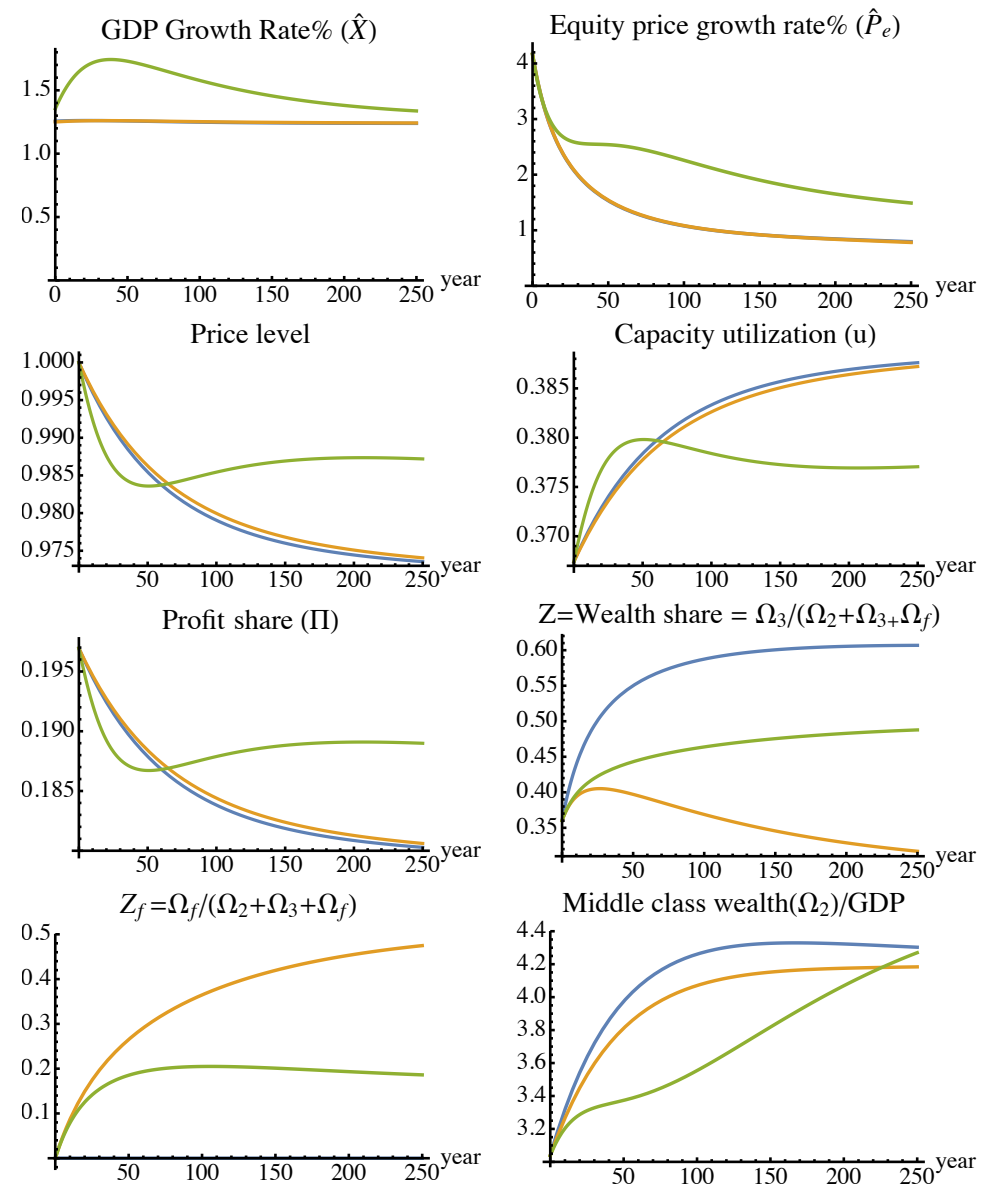

Middle class wealth $\left(\Omega_{2}\right) / \mathrm{GDP}$

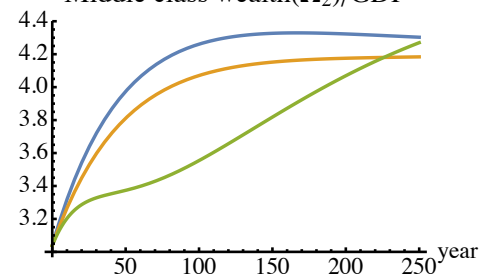

Top $1 \%$ wealth $\left(\Omega_{3}\right) / \mathrm{GDP}$
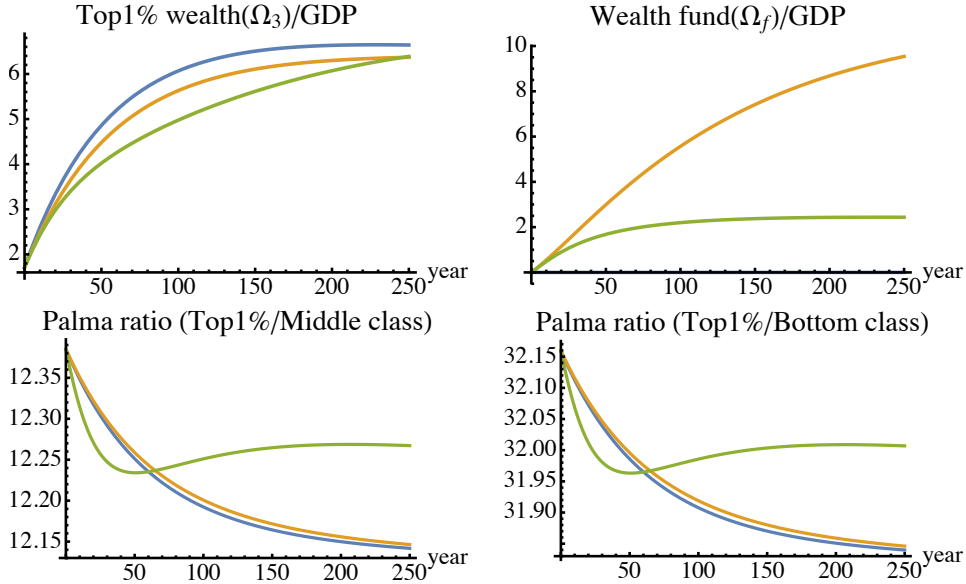

Figure 16: Original baseline (BLUE line) vs. wealth fund. ORANGE line represents wealth fund without transfer to government saving, and GREEN line represents wealth fund with $2 \%$ transfer to government saving 

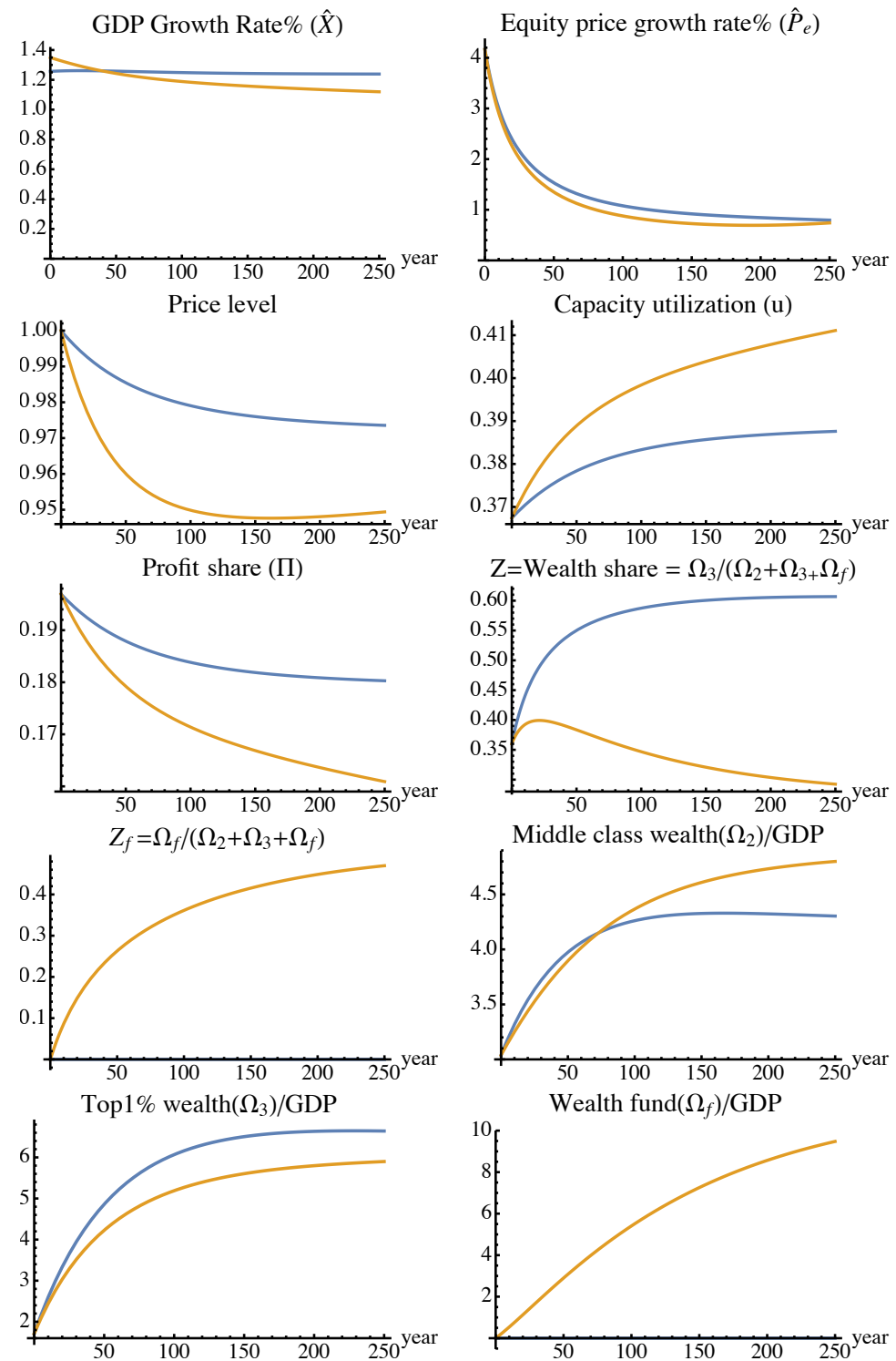

Wealth fund $\left(\Omega_{f}\right) / \mathrm{GDP}$
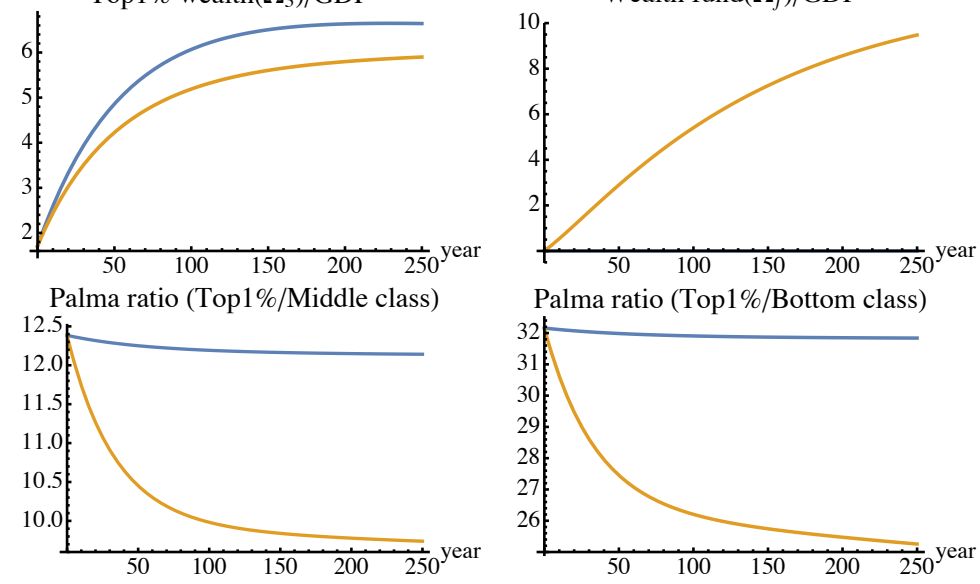

Figure 17: Original baseline (BLUE line) vs. combination of wealth fund (no transfer to government saving) with labor productivity growth and wage growth (ORANGE line) 